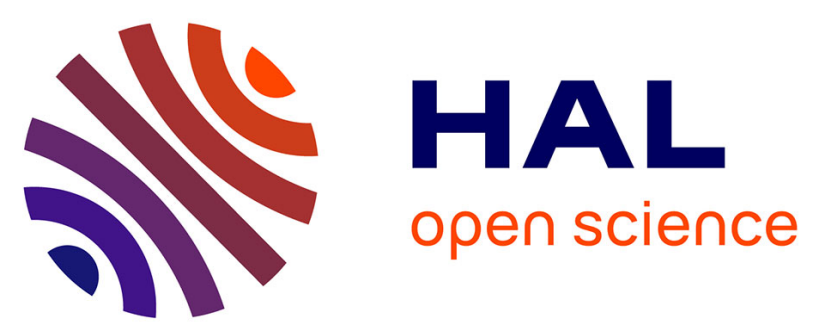

\title{
Analyses of High-Iron Sedimentary Bedrock and Diagenetic Features Observed With ChemCam at Vera Rubin Ridge, Gale Crater, Mars: Calibration and Characterization
}

\author{
G. David, A. Cousin, O. Forni, P.-y. Meslin, E. Dehouck, N. Mangold, J. \\ L'Haridon, W. Rapin, O. Gasnault, J. R. Johnson, et al.
}

\section{To cite this version:}

G. David, A. Cousin, O. Forni, P.-y. Meslin, E. Dehouck, et al.. Analyses of High-Iron Sedimentary Bedrock and Diagenetic Features Observed With ChemCam at Vera Rubin Ridge, Gale Crater, Mars: Calibration and Characterization. Journal of Geophysical Research. Planets, 2020, 125 (10), 10.1029/2019JE006314 . hal-03093150

\section{HAL Id: hal-03093150 https://hal.science/hal-03093150}

Submitted on 16 Jan 2021

HAL is a multi-disciplinary open access archive for the deposit and dissemination of scientific research documents, whether they are published or not. The documents may come from teaching and research institutions in France or abroad, or from public or private research centers.
L'archive ouverte pluridisciplinaire HAL, est destinée au dépôt et à la diffusion de documents scientifiques de niveau recherche, publiés ou non, émanant des établissements d'enseignement et de recherche français ou étrangers, des laboratoires publics ou privés. 
David Gaël (Orcid ID: 0000-0002-2719-1586)

Cousin Agnès (Orcid ID: 0000-0001-7823-7794)

Forni Olivier (Orcid ID: 0000-0001-6772-9689)

Meslin Pierre-Yves (Orcid ID: 0000-0002-0703-3951)

Dehouck Erwin (Orcid ID: 0000-0002-1368-4494)

Mangold Nicolas (Orcid ID: 0000-0002-0022-0631)

Rapin William (Orcid ID: 0000-0003-4660-8006)

Gasnault Olivier (Orcid ID: 0000-0002-6979-9012)

Johnson Jeffrey, R. (Orcid ID: 0000-0002-5586-4901)

Wiens Roger, C. (Orcid ID: 0000-0002-3409-7344)

\section{Analyses of high-iron sedimentary bedrock and diagenetic features observed with ChemCam at Vera Rubin ridge, Gale crater, Mars: calibration and characterization.}

\section{G. David ${ }^{1}$, A. Cousin ${ }^{1}$, O. Forni ${ }^{1}$, P-Y. Meslin ${ }^{1}$, E. Dehouck ${ }^{2}$, N. Mangold ${ }^{3}$, J.} L'Haridon $^{3}$, W. Rapin ${ }^{4}$, O. Gasnault ${ }^{1}$, J. R. Johnson ${ }^{5}$, A. M. Ollila ${ }^{6}$, A. R. Newell ${ }^{6}$, M. Salvatore $^{7}$, T. S. J. Gabriel ${ }^{8}$, R. C. Wiens ${ }^{6}$, S. Maurice ${ }^{1}$

${ }^{1}$ Institut de Recherche en Astrophysique et Planétologie, Université de Toulouse, UPS, CNRS, CNES, Toulouse, France

${ }^{2}$ Univ Lyon, Univ Lyon 1, ENSL, CNRS, LGL-TPE, F-69622, Villeurbanne, France

${ }^{3}$ Laboratoire de Planétologie et Géodynamique de Nantes, France

${ }^{4}$ California Institute of Technology, Pasadena, California, USA

${ }^{5}$ Johns Hopkins University, Applied Physics Laboratory, Laurel, Maryland, USA

${ }^{6}$ Los Alamos National Laboratory, Los Alamos, New Mexico, USA

${ }^{7}$ Northern Arizona University, Department of Physics and Astronomy, Flagstaff, Northern Arizona, USA

${ }^{8}$ Arizona State University, Tempe, Arizona, USA

Corresponding author: Gaël David (gdavid@irap.omp.eu)

\section{Key Points:}

- We present a dedicated ChemCam calibration for high-iron abundances and apply it to Vera Rubin ridge bedrock and diagenetic concretions

- Dark-toned diagenetic features have iron contents close to pure anhydrous iron oxides

- Iron variability is observed among bedrock in the upper part of the ridge, attributed to iron mobility during diagenesis

This article has been accepted for publication and undergone full peer review but has not been through the copyediting, typesetting, pagination and proofreading process which may lead to differences between this version and the Version of Record. Please cite this article as doi: 10.1029/2019JE006314 


\begin{abstract}
Curiosity investigated a topographic rise named Vera Rubin ridge (VRR) in Gale crater, for which a distinct hematite-like signature was observed from orbit. However, the ChemCam and APXS instruments on board the rover did not record any significant iron enrichment in the bulk of the ridge compared to previous terrains. For this study, we have re-verified ChemCam iron calibration at moderate abundances and developed more accurate calibrations at high-iron abundances using iron oxide mixtures in a basaltic matrix in order to complete the ChemCam calibration database. The high-iron calibration was first applied to the analysis of dark-toned diagenetic features encountered at several locations on VRR, which showed that their chemical compositions are close to pure anhydrous iron oxides. Then, we tracked iron abundances in the VRR bedrock and demonstrated that although there is no overall iron enrichment in the bulk of the ridge $\left(21.2 \pm 1.8 \mathrm{wt} . \% \mathrm{FeO}_{\mathrm{T}}\right)$ compared to underlying terrains, the iron content is more variable in its upper section with areas of enhanced iron abundances in the bedrock (up to $26.6 \pm 0.85 \mathrm{wt} . \% \mathrm{FeO}_{\mathrm{T}}$ ). Since the observed variability in iron abundances does not conform to the stratigraphy, the involvement of diagenetic fluid circulation was likely. An in-depth chemical study of these Fe-rich rocks reveals that spatial gradients in redox potential (Eh) may have driven iron mobility and reactions that precipitated and accumulated iron oxides. We hypothesize that slightly reducing fluids were probably involved in transporting ferrous iron. Mobile $\mathrm{Fe}^{2+}$ could have precipitated as iron oxides in more oxidizing conditions.
\end{abstract}

\title{
Plain Language Summary
}

Curiosity investigated a positive relief ridge named Vera Rubin ridge (VRR) located in the Gale crater. Orbital data indicates the presence of hematite (an iron oxide) in this ridge. Surprisingly, no significant enrichment in iron was observed by the two rover instruments (ChemCam and APXS), that determined the chemical compositions. Here, we have made a dedicated iron calibration for ChemCam martian data for high-iron abundances. For this, we prepared mixtures of basaltic powder and iron oxides (hematite, goethite, or magnetite) and analyzed them with a ChemCam laboratory unit. The objective was to increase the set of standards currently used for ChemCam iron quantification. This method has shown that darktoned concretions located in some VRR bedrock have an iron abundance similar to pure hematite. An iron survey along the ridge revealed that there is no overall enrichment compared to underlying terrains. However, iron abundances recorded in the upper part of the ridge are more variable. Areas of enhanced iron abundances do not follow the rock stratification, which suggests that the phenomenon responsible for the iron variability did not occur during the sediment deposition but rather occurred later, during diagenesis. Fluids percolating into the sediment are most likely responsible for iron mobility.

Keywords: Mars, ChemCam, Vera Rubin ridge, iron oxides, iron mobility

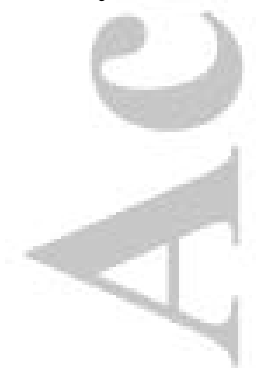




\section{Introduction}

The Mars Science Laboratory (MSL) rover Curiosity has been investigating Gale crater, on Mars, since August 2012. This crater formed 3.6 billion years ago in the Late Noachian/Early Hesperian [Thomson et al., 2011; Le Deit et al., 2013], and is located to the south of Elysium Planitia at the border of the Aeolis Mensae region. The rover is currently climbing Aeolis Mons (informally known as Mount Sharp), a $\sim 5 \mathrm{~km}$ tall mountain of which the lower layered sedimentary rocks contain a record of surface environmental variations over time [e.g., Milliken et al., 2010]. One of the main goals of the Mars Science Laboratory mission is to better constrain the past history of water and habitability on the surface of the planet and the evolution of its climate [Grotzinger et al., 2012]. Gale crater is the lowest topographic point for a thousand kilometers in any direction, enabling a rich hydrological history [Grotzinger et $a l ., 2015]$. Extensive fluvio-lacustrine activity was observed in the crater, as evidenced by geomorphologic features visible from orbit (e.g., Peace Vallis fan, [Palucis et al., 2014]) and detailed sedimentological observations from Curiosity (e.g., fluvial conglomerates and lacustrine mudstones, [Williams et al., 2013; Grotzinger et al., 2014]). Past fluvio-lacustrine activity reflects very different environmental conditions than currently observed in Gale crater. Geochemical and mineralogical data are also important to assess paleo-environments. Secondary minerals hold information about the environment of deposition and lithification. Mineralogy observed from orbit before Curiosity landed include the secondary products phyllosilicates, sulfates or iron oxide minerals along the slopes of Mount Sharp [Milliken et al., 2010; Thomson et al., 2011, Fraeman et al., 2016], and the relationship between mineralogy with different strata was thought to reflect varying depositional environments combined with post-depositional history. Constraining the chemistry of the sedimentary record of Gale crater is an important means to understand the past conditions of the planet and its evolution.

In this work, we focus on Curiosity's observations at Vera Rubin ridge (VRR), which is located on the lower slopes of Mount Sharp. Spectral reflectance data from the Compact Reconnaissance Imaging Spectrometer for Mars (CRISM) instrument [Murchie et al., 2007] showed a clear signature of red crystalline hematite associated with VRR [Fraeman et al., 2013; this issue]. However, Curiosity reached VRR around sol (martian day) 1800 of the mission and neither the Chemistry \& Camera (ChemCam, [Maurice et al., 2012; Wiens et al., 2012]) nor the Alpha Particle X-ray Spectrometer (APXS, [Campbell et al., 2012]) recorded any significant iron enrichment in the bulk composition of the ridge relative to underlying terrains [Frydenvang et al., 2019; this issue, Thompson et al., 2019, this issue]. On the other hand, sporadic mm-scale Fe-rich diagenetic features have been observed in the form of darktoned nodular concretions within or in close association with light-toned calcium sulfate veins on VRR [ $L$ 'Haridon et al., this issue]. Due to their very fine scale, areal coverage and spectral properties, these features are unlikely the source of the spectral features observed with CRISM. But from a ChemCam perspective, these dark-toned features consisted of $\geq 36 \mathrm{wt} . \% \mathrm{FeO}_{\mathrm{T}}$ with the current Major Oxide Composition quantification method (MOC, [Clegg et al., 2017]). However, these high values are beyond the range of most of the $\mathrm{FeO}_{\mathrm{T}}$ abundances present in reference samples for the ChemCam's calibration, so that pure or nearly pure phases could not be ruled out, e.g., as in hematite-rich concretions. High-Fe compositions are not sufficiently represented in the ChemCam calibration database used in 2017, especially in terms of hematite mixtures. For this study, we have re-validated and refined the ChemCam iron calibration using iron oxide mixtures in a basaltic matrix. The goal of this work was to study VRR iron oxides and their formation conditions. We propose a specific model for iron quantification in Fe-oxide mixtures, particularly for VRR where hematite is one of the major Fe-bearing phases [Rampe et al., this issue]. It was important to check the Fe calibration for VRR given that the first 
measurements did not show the expected iron increase. In this paper, we first describe the use of additional reference samples to refine the ChemCam calibration for high-iron abundances. Then, we apply our laboratory results to the ChemCam data acquired on VRR in order to identify iron-rich materials and precisely quantify their iron abundances. These iron-rich materials include dark-toned diagenetic features and localized iron enrichments in the bedrock. The diagenetic features and their formation processes are described, morphologically and chemically, in L'Haridon et al., (this issue), and interpretations in that paper focus on the role of fluids in the bedrock to explain these diagenetic features. The present work focuses at difference in iron abundances in the bedrock at a larger scale, and on their implications in relation to the diagenetic history of the various members of the ridge.

\section{VRR geological setting}

VRR is a $\sim 200 \mathrm{~m}$ wide and $\sim 6.5 \mathrm{~km}$ long distinct topographic and textural sedimentary feature [Fraeman et al., 2013], within the Murray formation. The Murray formation is more than $300 \mathrm{~m}$ thick section of mudstones interpreted to have been deposited in a lake or lake margin [Grotzinger et al., 2015; Stack et al., 2019]. The Murray formation below VRR is subdivided into five lithostratigraphic members named the Pahrump Hills member, Hartmann's Valley member, Karasburg member, Sutton Island member and Blunts Point member [Fedo et al., 2019]. No unconformity was observed in situ between the top of the Blunts Point member and base of VRR. The bedding orientations within the ridge are relatively horizontal, similar to the strata below, which implies a depositional continuity between the different members of the Murray formation and that the ridge is part of the original Mount Sharp stratigraphic sequence [Bennett et al., this issue; Edgar et al., this issue, Stein et al., this issue]. Similarly, only limited chemical variations were documented by ChemCam in the bedrock [Frydenvang et al., this issue]. In addition to a clear hematite-like spectral orbital signature, the ridge appears to have higher orbital thermal inertia and is more resistant to erosion than the other adjacent Murray terrains [Fraeman et al., 2016]. The increase of rock hardness - making the drilling process difficult (Voyageurs, Ailsa_Craig and Inverness drill targets were aborted, c.f. [Jacob et al., this issue] - also contrasts with underlying Murray terrains, and could reflect the presence of greater cementation in the bedrock.

Based on in situ and orbital observations, VRR was divided into two lithostratigraphic members within the Murray formation named the Pettegrove Point member (PP) and the Jura member. Sediments within these members were thought to be deposited in a low-energy lacustrine environment as suggested by the persistent fine laminations $(0.22-0.59 \mathrm{~mm}$, [Edgar et al., this issue]). This observation coupled with the lack of desiccation features suggests a deposition in a lake with a stable water level [Fedo et al., 2019]. The boundaries at the base of VRR, defined by a break in the local slope, and between the two members of VRR do not conform to elevation. This suggests a diagenetic origin to the ridge and/or other postdepositional process, e.g., differential compaction [Edgar et al., this issue].

The Pettegrove Point member is the lowest part of VRR and consists of well-cemented, finely laminated mudstones. The Jura member, which is also composed predominantly of finely laminated mudstone conformably lying on top of the Pettegrove Point member, is on average darker than the underlying member. This member also shows lateral color variations from red to grey (hereafter referred as "red Jura" and "grey Jura"). The bedrock of the grey Jura occurs in meter to tens of meter-sized patches that often form shallow depressions along the top of the ridge. Unlike red Jura, Ca-sulfate veins located in the grey Jura are more irregular, with a rugged texture, and appeared more resistant to erosion compared to surrounding bedrock. In close association with these veins, millimeter-scale dark-toned features were observed, 
exhibiting several unique morphologies including crystal molds, nodular concretions, and darktoned vein fills [L'Haridon et al., this issue]. Due to their millimeter to sub-millimeter scale, precise pointing with the ChemCam LIBS (Laser-Induced Breakdown Spectroscopy) instrument was challenging, but these features showed one of the highest $\mathrm{FeO}_{\mathrm{T}}$ contents probed with this instrument since the beginning of the mission. Bleached host rocks depleted in iron (mainly < 10 wt.\% $\mathrm{FeO}_{\mathrm{T}}$ ) were locally observed in the vicinity of these dark-toned features, which hints at a genetic link with the high-Fe dark-toned features, with iron mobility potentially driven by a redox process as discussed in [L'Haridon et al., this issue].

In order to obtain constraints on the mineralogy with the Chemistry \& Mineralogy (CheMin, [Blake et al., 2012]) and Sample Analysis at Mars (SAM, [Mahaffy et al., 2012]) instruments, three drilled samples were acquired on VRR: Stoer (ST) in the Pettegrove Point member, Rock Hall (RH) in the red Jura member and Highfield (HF) in the grey Jura member. At Stoer, the CheMin instrument, an X-ray diffractometer, recorded feldspar $\left(\mathrm{An}_{41( \pm 0.4)} \mathrm{Ab}_{59( \pm 0.4)}\right)$, hematite, and phyllosilicate as the major crystalline minerals [Rampe et al., this issue], and X-ray amorphous materials (38 wt.\%). Minor phases in the Stoer sample include pyroxene, magnetite, akaganeite and jarosite in addition to calcium sulfates (anhydrite, gypsum, and bassanite). The mineralogical analysis at the Rock Hall drill location (red Jura) reveals the presence of amorphous phases (34 wt.\%), iron oxides (akaganeite and hematite), sulfate minerals (anhydrite and jarosite), and possibly of fluorapatite. There are also igneous minerals including plagioclase feldspar and pyroxene, in different abundances than at Pettegrove Point (respectively $-3 \mathrm{wt} . \%$ and $+5.8 \mathrm{wt} . \%$ relative to whole rock concentrations, [Rampe et al., this issue]), but no K-feldspar. Mineral phases present in the Highfield drill location (grey Jura) show differences compared to the red Jura, especially with the presence of grey hematite [Rampe et al., this issue] and the lack of akaganeite and jarosite. Abondant amorphous component is also presnt (49 wt.\%). The lack of ferric absorption features in ChemCam passive reflectance observations (made without utilization of the laser, [Johnson et al., 2015, 2016] and Mastcam multispectral observations suggest that specular grey hematite could be located in the grey Jura samples [Jacob et al., this issue; Horgan et al., 2019, this issue, L'Haridon et al., this issue]. The color of hematite turns grey instead of red when particle sizes are greater than $\sim 5 \mu \mathrm{m}$ (e.g., [Sherman et al., 1985; Catling and Moore, 2003]). The smaller full-width at half maximum (FWHM) of the hematite peak measured by the CheMin instrument is also evidence for a greater hematite crystallite size in the VRR samples compared to the Blunts Point sample [Rampe et al., this issue].

\section{Methods and Data}

3.1 Sample selection and preparation

The iron quantification refinements developed in this study are based on laboratory LIBS spectra from the current MOC sample reference database [Clegg et al., 2017] and enhanced with additional mixtures of basaltic materials and iron oxides prepared specifically for this study, and analyzed with a ChemCam laboratory unit. Each iron oxide was mixed with the martian regolith simulant JSC Mars-1 [Allen et al., 1998]. The basaltic analog used in our experiment, which is considered as a close spectral analog to the bright region of Mars [Evans et al., 1979], is composed of altered glassy ashes and cinders from the Pu'u Nene volcanic cone on Mauna Kea, Hawaii. It contains mostly amorphous palagonite with anorthite, Ti-rich magnetite, hematite, pyroxene, olivine, and nanophases ferric oxides. Therefore although the JSC Mars- 1 is among the most used martian simulants, it is not a perfect simulant for the VRR bedrock. It shows some differences in terms of mineralogy, but also in chemistry. Specifically, compared to the average composition of the VRR bedrock, it shows lower $\mathrm{SiO}_{2}, \mathrm{MgO}, \mathrm{FeO}_{\mathrm{T}}$, 
$\mathrm{Na}_{2} \mathrm{O}, \mathrm{K}_{2} \mathrm{O}$ abundances, and higher $\mathrm{TiO}_{2}, \mathrm{Al}_{2} \mathrm{O}_{3}$, and $\mathrm{CaO}$ abundances (see supplementary material table S1). However, this material was selected for our experiments due to its relatively high iron content in the fine fraction. Indeed, the simulant was sieved and only the finest fraction of the powder $(<45 \mu \mathrm{m})$ was kept. The sieving enabled us to prepare mixtures with a particle size much smaller than the ChemCam focused laser beam diameter $(\sim 425 \pm 25 \mu \mathrm{m}$, Chide et al., 2019; Maurice et al., 2012), and consequently to minimize heterogeneity issues in our LIBS analyses. Chemical analyses of the fine fraction of the JSC Mars-1 material were performed using Laser Ablation Inductively Coupled Plasma Mass Spectrometry (LA-ICPMS, 8 observation points with a sampling area of $60 \mu \mathrm{m}$ ); they show that the iron content is $\sim 16.5$ wt.\% $\mathrm{FeO}_{\mathrm{T}}$ (see supplementary material table $\mathrm{S} 1$ and table S2, David 2020c), which is still lower than the average VRR bedrock ( $20 \mathrm{wt} . \% \mathrm{FeO}_{\mathrm{T}}$, [Frydenvang et al., 2019, this issue]. Consequently, natural ilmenite $\left(\mathrm{Fe}^{2+} \mathrm{TiO}_{3}\right)$ was added to the simulant (14 wt.\% ilmenite and 86 wt.\% JSC Mars-1) to bring the iron abundance of the mixture to the typical level of Gale rocks. The ilmenite powder composition was also analyzed with LA-ICPMS (see supplementary material table S2).

Then this mixture (JSC Mars-1 simulant with ilmenite) was mixed with three different iron oxide phases (hematite, goethite, and magnetite) in different samples. These iron oxides were selected because they are known to occur on the martian surface. The most thermodynamically stable mineral under present martian conditions is hematite [Gooding et al., 1978; Morris et al., 1989], which has been observed in many locations on Mars. Hematite $\left(\mathrm{Fe}^{3+}{ }_{2} \mathrm{O}_{3}\right)$ is the final product of many chemical and thermal transformation pathways of other iron oxides [Barron et al., 2002; Morris et al., 1998]. Crystalline hematite occurrences are widespread on the martian surface as observed from orbit (e.g., [Christensen et al., 2000; 2001] or in situ as minerals (e.g., in Gusev and Gale craters [Morris et al., 2006; Rampe et al.,2017]) or as diagenetic concretions as observed in Meridiani Planum [McLennan et al., 2005]. Nanophase hematite is also thought to be present in martian dust (e.g., [Morris et al., 1989]).

The second iron oxide species used in our samples is magnetite $\left(\mathrm{Fe}^{3+}{ }_{2} \mathrm{Fe}^{2+} \mathrm{O}_{4}\right)$. Similar to hematite, magnetite was observed in both Gusev [Morris et al., 2006] and Gale craters [Rampe et al., 2017], and martian dust (e.g., (Goetz et al., 2005]). During Curiosity's traverse, magnetite was observed in the Bradbury group sedimentary rocks, from the Yellowknife Bay formation unit to Pahrump Hills [Rampe et al., 2017; Hurowitz et al., 2017; Morrison et al., 2018]. Hematite dominates most of the Murray formation rocks, from Pahrump Hills up to VRR, except the Telegraph Peak and Bucksin drilled samples, where magnetite was the primary iron oxide phase.

The third mineral used in our experiment is goethite $\left(\mathrm{Fe}^{3+} \mathrm{O}(\mathrm{OH})\right)$, which is an iron oxyhydroxide that forms under aqueous conditions. It is not thermodynamically stable at the martian surface [Fish et al., 1966, Burns et al., 1990] but as it is a long-timescale metastable phase, goethite can be still observed in martian rocks as an indicator of paleoenvironmental conditions suitable for goethite formation. Goethite was detected for example on the plains and in the Columbia Hills of Gusev crater [Morris et al., 2006], but not yet in Gale crater. Goethite was also observed in martian meteorites [Bridges et al., 2001]. This iron oxide is an important potential candidate precursor to the widespread martian hematite by dehydration [Zolotov et al., 2005; Glotch et al., 2004].

Each iron oxide was mixed with the martian regolith simulant JSC Mars-1/ilmenite mixture, at different concentrations (from $0 \%$ up to $100 \mathrm{wt} . \%$ for hematite and goethite mixtures, and from $0 \%$ up to $25 \mathrm{wt} . \%$ for magnetite mixtures; see mixture proportion and composition in supplementary material table $\mathrm{S} 2$, in the section on mixture compositions). 
These additional basaltic mixtures are aimed to complete the ChemCam calibration database [Clegg et al., 2017] that has relatively few standards with iron abundances greater than $20 \mathrm{wt} . \%$ $\mathrm{FeO}_{\mathrm{T}}$ (only 14 from over 408). The step size in the range of composition between 20-30 wt.\% $\mathrm{FeO}_{\mathrm{T}}$ in our samples is intentionally low, in order to have a more accurate iron abundance for small iron variations in the VRR bedrock.

One supplementary set was made consisting of a mixture of JSC Mars-1 (without ilmenite) and hematite (2, 5, 8, 24, 45 and $72 \mathrm{wt} \% \%$ hematite). Additional mixtures were prepared between JSC Mars-1 and Mg-sulfate (kieserite) and between JSC Mars-1 (with and without ilmenite) and Ca-sulfates (1:1:1 mixture of anhydrite, bassanite, and gypsum). Additional reference basaltic material such as BHVO2 [Wilson, 1997] was also mixed with a few percent hematite powder $(0.5,1,2$ and 3 wt.\% hematite). Finally, one sample of pure Mojave Mars simulant (Peters et al., 2008) was also prepared. These additional materials were used in our study to have some points with "low" abundances of iron $\left(<20 \mathrm{wt} . \% \mathrm{FeO}_{\mathrm{T}}\right)$.

Reference compositions for hematite, goethite and the Mojave sand were obtained thanks to ICPMS analyses. Magnetite, Ca-sulfates and Mg-sulfate powders were theoretical but they are commercial products (purity $>97 \%$ ). Sulfate products were also commercial reagent powders, and the mineralogy of the Ca-sulfates was measured using Raman spectroscopy [Rapin et al., 2016]. Iron abundance of the BHVO2 was obtained from literature [Wilson, 1997]. Finally, each iron content per mixture was calculated considering a weighted sum of materials implied.

Mixtures were compacted under 10 tons of pressure to obtain indurated pressed pellets (13mm diameter), which were hard enough to be analyzed by the LIBS laser beam. Each pellet was probed on 5 different locations with the ChemCam clone in the laboratory to minimize heterogeneity effects in the sample. Each laser burst included 30 shots.

\subsection{ChemCam flight model and IRAP setup}

The ChemCam LIBS instrument onboard the Curiosity rover probes elemental chemistry remotely at a sub-millimeter scale. ChemCam uses a Nd: KGW nanosecond pulsed laser at $1067 \mathrm{~nm}$ to ablate rocks and soils, with a frequency ranging from 1 to $10 \mathrm{~Hz}$, and laser power on target of $14 \mathrm{~mJ}$ [Maurice et al., 2012]. The three spectrometers of the ChemCam instrument, located on the body unit of the rover, cover the spectral ranges of ultraviolet (UV: 240.1-342.2 nm), violet (VIO: 382.1-469.3 nm) and visible and near-infrared (VNIR: 474$906.5 \mathrm{~nm}$ ), with a spectral resolution respectively of $0.15 \mathrm{~nm}, 0.20 \mathrm{~nm}$ and $0.65 \mathrm{~nm}$ [Wiens et al., 2012]. These spectrometers capture the emission spectrum of the plasma created by the interaction between the surface material and the laser (during $3 \mathrm{~ms}$ for martian standard measurement). The plasma contains ionized species that emit photons during radiative decay at wavelengths characteristic of the elements present in the sample (e.g., [Knight et al., 2000]). The laser beam has a sampling area that ranges from 350 to $550 \mu \mathrm{m}$ [Maurice et al., 2012; 2016], depending mostly on the distance of the target (between 2 to 7 meters), enabling to probe at very fine scale geological targets. By way of comparison, the APXS instrument has a spatial resolution of $1.7 \mathrm{~cm}$ [Campbell et al, 2012] at its closest position to the target, providing a complementary bulk composition. With ChemCam, repeated shots on the same point (30 for a standard measurement) remove large amounts of dust from the surface of the rocks [Maurice et al., 2016; Lasue et al., 2018] and can be used to study chemical variability with depth (e.g., [Lanza et al., 2012]). Geological context and localization of LIBS pits are documented with the Remote Micro-Imaging system [Maurice et al., 2012; Le Mouélic et al., 2015], which can resolve details of ChemCam targets with $\sim 50 \mu \mathrm{rad}$ resolution. For each ChemCam observation 
point, dark spectra are acquired (spectra without laser, called passive mode) in order to remove the ambient light reflected by the sample and to correct the thermal noise of the CCD on active spectra. Although ChemCam spectrometers were not designed for reflectance spectroscopy, they have enough sensitivity to provide some mineralogical information on surface targets through the use of passive relative reflectance spectroscopy [Johnson et al., 2015; 2016].

In active mode (LIBS mode), most major rock-forming elements, typically reported as oxides $\left(\mathrm{SiO}_{2}, \mathrm{CaO}, \mathrm{MgO}, \mathrm{Al}_{2} \mathrm{O}_{3}, \mathrm{~K}_{2} \mathrm{O}, \mathrm{Na}_{2} \mathrm{O}, \mathrm{TiO}_{2}\right.$, and $\left.\mathrm{FeO}_{\mathrm{T}}\right)$ can be detected and quantified with the ChemCam instrument [Wiens et al., 2013; Clegg et al., 2017]. ChemCam is also sensitive to some minor and trace elements, including $\mathrm{H}, \mathrm{Li}, \mathrm{F}, \mathrm{Cl}, \mathrm{P}, \mathrm{Cr}, \mathrm{Mn}, \mathrm{Cu}, \mathrm{Zn}, \mathrm{Rb}, \mathrm{Sr}$, S, Ni, C and Ba [Ollila et al., 2014; Lanza et al., 2014; Forni et al., 2015; Rapin et al., 2016; Lasue et al., 2016; Payré et al., 2017; Meslin et al., 2018, Payré et al., 2019]. The current MOC quantification routine combines two multivariate methods: the Partial Least Squares [Clegg et al., 2009, Anderson et al., 2017b] and the Independent Component Analysis [Forni et al., 2013]. Multivariate analyses use the entire spectrum rather than a single peak and consequently are less subject to matrix effects, which allows better elemental estimation. The introduction of this new approach was accompanied by the extension of the calibration database from 66 to 408 standards leading to vast improvements of the quantification, especially for extreme compositions [Clegg et al., 2017]. However, for specific end-members like pure iron oxide, the expanded database is still insufficient as it contains only 2 samples with $\mathrm{FeO}_{\text {T }}$ contents above 49 wt.\% (natural hematite and a mixture of basaltic material and hematite). This gap leads to an underestimation of $\mathrm{FeO}_{\mathrm{T}}$ in iron-rich martian targets (and probably to an overestimation of other elements, as observed in iron meteorite samples [Meslin et al., 2017; 2019]). This makes it problematic when tracking and studying enriched iron oxides in VRR. The abundances of major elements measured by ChemCam on VRR and how they vary generally with the Murray formation stratigraphy are reported in Frydenvang et al., [this issue].

A ChemCam instrument is available at the IRAP laboratory consisting of the EQM version (Engineering Qualification Model) for the Mast Unit, and the EM (Engineering Model) for the Body Unit (for a more detailed description, see Cousin et al., [2011] or Rapin et al., [2016]). The instrument is located in a thermal chamber cooled at $-10^{\circ} \mathrm{C}$, the laser's optimal operating temperature, which allows to reach the same level of laser energy per pulse $(\sim 10 \mathrm{~mJ})$ as the ChemCam flight instrument on Mars $(\sim 14 \mathrm{~mJ})$. On the other hand, samples are located in a separate martian chamber, allowing the laser-matter interaction to occur under Mars surface atmospheric pressure ( $\sim 7$ mbar) and composition (mainly $\mathrm{CO}_{2}, 1.6 \%$ Ar and $2.7 \% \mathrm{~N}_{2}$ ). Atmospheric pressure and composition are important parameters to reproduce martian measurements because they have strong impacts on the spectral intensity and resolution, and also in the detection limits of species [Knight et al., 2000, Colao et al., 2004; Effenberger et al., 2010; Lasue et al., 2012]. To make the samples degas and release their volatiles, the chamber was pumped to vacuum $\left(10^{-3} \mathrm{mbar}\right)$ for several hours before introducing the martian simulant atmospheric gases. Finally, the pre-processing of the laboratory data was done similarly to martian data [Wiens et al., 2013], to obtain clean and calibrated spectra.

\subsection{Iron quantification method}

In order to minimize spectral intensity fluctuations related to variations in target properties, each spectrum acquired on geological targets is normalized. Many factors inherent to the LIBS technique can be responsible for variations in the spectra, including differences in laser irradiance due to focus quality (or distance of the target) as well as coupling issues due to the optical properties of the targets. Similarly to the ChemCam MOC quantification method, the appropriate method of normalization of laboratory samples is dependent on the iron 
abundance in the sample [Clegg et al., 2017; Anderson et al., 2017b]. For iron abundances higher than $17 \mathrm{wt} . \% \mathrm{FeO}_{\mathrm{T}}$ in the sample, each pixel of the spectrum is divided by the total emission intensity of the three spectrometers (referred to "Norm1" in Clegg et al., [2017] such that the sum of all normalized pixels is equal to 1). Conversely, for iron abundance lower than $15 \mathrm{wt} . \% \mathrm{FeO}_{\mathrm{T}}$ in the sample, each pixel of a given spectrometer is divided by the total emission intensity of the corresponding spectrometer (referred to "Norm3" in Clegg et al., [2017] such that the sum of the normalized pixels from the three spectrometers is equal to 3 ). In the 15-17 wt. $\% \mathrm{FeO}_{\mathrm{T}}$ compositional range, a blend model corresponding to a linear weighted sum of the two aforementioned sub-models is used [Anderson et al., 2017b].

The ChemCam laboratory setup in Toulouse (France) and the flight instrument have different instrumental responses, especially due to the set of additional windows and folding mirror in the optical pathway of the former. Consequently, the quantification routine used for martian data (the MOC algorithm) cannot be directly applied to our laboratory data. Applying the MOC method to the data obtained with the setup in Toulouse would require us to run the entire set of calibration standards with that setup as it was done at the Los Alamos National Laboratory [Clegg et al., 2017]. To avoid this issue, we used a similar approach as the ICA (Independent Component Analysis) algorithm, used with ChemCam data [Forni et al., 2013]. Our method of iron quantification is based on the determination of the linear Pearson correlation coefficient between the spectrum of each geological sample and the spectrum of an iron reference. This Fe correlation factor is directly correlated to the iron abundance in the sample, which enabled us to build an iron regression curve (Figure 1). However, while ICA uses an independent component as the reference spectrum for iron quantification extracted from martian spectra with the Joint Approximate Diagonalization of Eigenmatrices (JADE) algorithm (e.g., [Cardoso et al., 1993; 1997; Forni et al., 2013] for details about algorithm), we used a spectrum obtained on natural samples of almost pure iron. The iron reference used is dependent on the dataset. For terrestrial analyses, we used the spectrum of the Mont Dieu iron meteorite (> 92 Fe wt.\%, [Desrousseaux et al., 1997] as our iron standard. A similar iron meteorite was probed with the ChemCam instrument on Mars, and is used as a reference for martian spectra: the Aeolis Mons 001 (or Egg Rock from the name of the ChemCam target at sol 1505, [Meslin et al., 2017; 2019]). Both meteorites have very similar LIBS spectra highly dominated by iron peaks [Meslin et al., 2017]. Nickel abundances are also relatively similar between the Mont Dieu and Egg Rock meteorites with respectively $\sim 7.6$ and $\sim 5 \mathrm{wt} . \% \mathrm{Ni}$ [Desrousseaux et al., 1997; Meslin et al., 2019]. However, to minimize the effects of small chemical differences and of different optical transmission functions between the instruments, we masked all wavelengths that showed a strong divergence in intensity between the two iron meteorites' spectra. First, we removed the wavelengths at the edges of the three spectrometers (also done for the MOC method [Clegg et al., 2017]) as these ranges have the greatest differences in the instrument transmission functions $(240-251.45 \mathrm{~nm}, 340.5-388.09 \mathrm{~nm}$ and 473.2-496.7 nm). Then, most of the VNIR range was masked as there is no Fe line in that part of the spectra $(563.64-905.6 \mathrm{~nm})$. Linear regression was calculated from the intensities of both spectra (I $\mathrm{I}_{\text {Mont Dieu Vs. }} \mathrm{I}_{\mathrm{Egg} \text { Rock}}$ ) of these remaining pixels that correspond to the best correlation. The correlation parameters $a=0.8$. and $b=-4.26 \mathrm{E}-7$ are different than a $1: 1$ line because the two spectra have differences in total intensity. Then for each wavelength of the spectra, the absolute difference between the two spectra ( $\mathrm{I}_{\text {Mont Dieu }}$ - $\left.\mathrm{I}_{\text {Egg Rock }}\right)$ was calculated, as well as a threshold (d) set to the median absolute deviation of all these differences. Then, for each wavelength $i$, if the absolute difference observed between the two spectra at this wavelength was higher than $\mathrm{E}$ the wavelength was masked, where E can be expressed as :

$$
\mathrm{E}=\left(\mathrm{I}_{\text {Mont Dieu }}(i)-\left(\mathrm{a} * \mathrm{I}_{\text {Mont Dieu }}(i)+\mathrm{b}+\mathrm{d}\right)\right.
$$


The next step consisted in removing the wavelengths that may be the source of interference between iron emission peaks and other chemical elements. In the spectral range covered by the three spectrometers, iron and titanium have the highest number of emission peaks, which sometimes overlap, especially in the UV spectral range. To avoid problematic bias in our method due to interference with titanium peaks, we removed from our spectra all spectral regions with titanium contributions. Titanium emission peaks were identified using the JADE algorithm applied to our laboratory data, also used in the ICA method [Forni et al., 2013]. From this titanium spectrum, we empirically identified all the Ti emission peaks. In addition to $\mathrm{Ti}$ interference, we also removed strong emission peaks linked to $\mathrm{Mg}$ and $\mathrm{Ca}$ elements that are also potential sources of interference with iron. The list of selected wavelengths can be found in the supplementary material table S3, (David. 2020c). From the original 6144 channels of our LIBS spectra, the final spectrum was made of 1406 channels, including wavelengths from the three spectral regions (from UV to VNIR).

To develop our improved high-iron calibration, we also used spectra from the ChemCam calibration database, which were acquired at the Los Alamos National Laboratory using the EM of the Mast Unit and the EQM of the Body Unit [Clegg et al., 2017]. For this dataset (see supplementary material table S2, in the section on the ChemCam calibration database), the iron reference used corresponds to a spectrum of a pure hematite sample acquired with the LANL setup. This iron reference was processed the same way as described above. Hematite, goethite, and magnetite mixtures were also analyzed with the LANL experimental setup. This enables us to check that the method gives consistent results when using two different ChemCam setups.

The linear Pearson correlation coefficient between the spectrum of each geological sample and the spectrum of an iron reference (terrestrial or martian references depending on the LIBS dataset used) is shown in Figure 1.a. Samples with heterogeneity issues (due to imperfect mixing or varying grain sizes) were removed from the dataset. The standard deviation and the average for each sample were computed from the iron correlation factors obtained on the five observation points. The sample was removed if the standard deviation value was higher than the heterogeneity threshold (defined as the mean of all standard deviations $+2 \sigma$ ). The number of samples as a function of the known $\mathrm{FeO}_{\mathrm{T}}$ composition can be found in Figure 2.a.

The linear Pearson correlation coefficients as a function of the $\mathrm{FeO}_{\mathrm{T}}$ abundances were fitted with a fourth-degree polynomial function (dashed line in Figure 1.a). A $3^{\text {rd }}$ degree (and lower) and a $5^{\text {th }}$ degree polynomial curves are not able to fit efficiently all points of the calibration database and show higher residuals. The calibration curve does not show a linear correlation between the Fe correlation factor and the iron abundance in the samples. Instead, the curve illustrates the challenge to quantify Fe-rich targets because a small variation in the signal corresponds to a large variation in the predicted abundance, thus justifying this dedicated work. Such a phenomenon is inherent to the method used and linked to the behavior of iron emission peaks. Indeed, beyond a certain iron abundance $\left(\sim 30 \mathrm{wt} . \% \mathrm{FeO}_{\mathrm{T}}\right)$, iron peak intensities evolve much more slowly with increasing iron concentration, and other majorelement peaks are negligible. In other words, as the intensity is not correlated linearly with concentration, this leads to a change in the slope of the model.

Among the five observation points in each sample, the scatter of iron correlation factors was relatively low (once heterogeneous outliers were removed). It means that the repeatability of the LIBS analysis per sample is good, and the scatter among observation points observed in the Figure 1.a (especially in the lower iron abundances of the regression curve) is intersample 
rather than intrasample. This is due to chemical matrix effects between samples, induced by the large range of mineralogical assemblages used to build the model. Consequently, we are confident in the ability of the model to track small variations in iron content in Gale crater rocks, as the mineralogical assemblage in a given stratigraphic member is not expected to show drastic change.

The model uncertainty on iron quantification is defined by the root-mean-square error of prediction (RMSE), defined as follows:

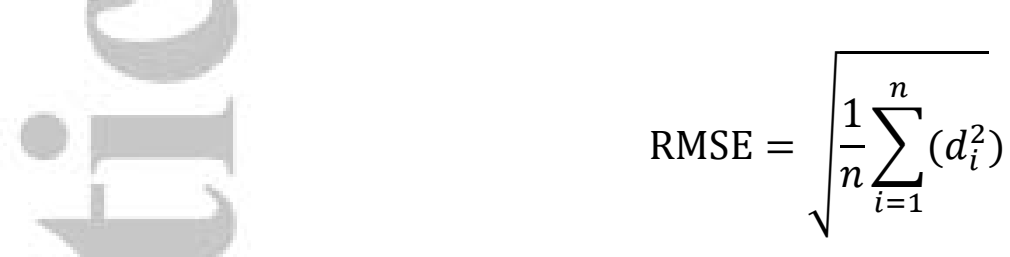

In equation (1), $d$ is defined as the difference between predicted and known compositions of the sample, and $n$ corresponds to the number of samples in the model. The enhancement of the ChemCam calibration database by our mixtures brings the number of spectra in our model to 70,500 (or 2350 observation points) from 437 different laboratory samples. For each iron abundance, a corresponding RMSE is calculated based on all of the samples that have iron abundances within a window of $\pm 10 \mathrm{wt} . \% \mathrm{FeO}_{\mathrm{T}}$. The results are presented in Figure 2.b. The level of confidence in the RMSE is dependent on the total number of samples per compositional range (Figure 2.a). As an example, the RMSE calculated for iron abundances typical of Gale crater bedrock $\left(\sim 20 \mathrm{wt} . \% \mathrm{FeO}_{\mathrm{T}}\right.$ from the MOC quantification method) is lower than $3 \mathrm{wt} \% \mathrm{FeO}_{\mathrm{T}}$. The Pearson coefficient calibration becomes quite inaccurate between 40-60 wt. $\% \mathrm{FeO}_{\mathrm{T}}$, but appears to improve again at $\sim 80-100$ wt. $\% \mathrm{FeO}_{\mathrm{T}}$ with a RMSE for pure iron oxide lower than $7 \mathrm{wt} . \% \mathrm{FeO}_{\mathrm{T}}$.

Comparing with the standard $\mathrm{FeO}_{\mathrm{T}}$ abundances archived by the project in the Planetary Data System (MOC, [Clegg et al., 2017]), this calibration curve provides essentially identical results up to $\sim 23 \mathrm{wt}$. \% $\mathrm{FeO}_{\mathrm{T}}$ from $\mathrm{MOC}$ (see supplementary material Figure S1), e.g., for nearly all of the $>20,000$ Mars observation points quantified by ChemCam. Indeed, only less than 10 $\%$ of ChemCam observation points appear to be underestimated with the MOC quantification method. This result gives strong confidence that the standard MOC compositions are appropriate over the typical range of $\mathrm{FeO}_{\mathrm{T}}$ for Gale targets. Above $\sim 30$ wt. $\% \mathrm{FeO}_{\mathrm{T}}$, the calibration in this work tends toward higher iron abundances than MOC. Given the relatively few standards used for MOC at high-Fe abundances, this is not too surprising, and due to this fact, MOC abundances $>36 \mathrm{wt} . \% \mathrm{FeO}_{\mathrm{T}}$ have not been validated or archived over the course of the mission.

\subsection{Limit of detection of excess iron}

In this section, we defined the limits of our iron quantification model for which we are able to observe an excess of iron (or iron oxides) from a certain level of abundance considered as reference. For this purpose, we used the critical level $\left(\mathrm{L}_{\mathrm{c}}\right)$ and the limit of detection (LOD) concepts [Curie et al., 1968]. For a ChemCam-like setup, both parameters were estimated from all laboratory samples used to build the iron quantification method. The LOD corresponds to the true net lowest iron concentration that can be reliably detected with respect to a blank sample and considering false negatives and positives (with a given level of confidence, here chosen to be $97.5 \%$ ). The $\mathrm{L}_{\mathrm{c}}$ is defined with respect to false positives only (at the $97.5 \%$ 
confidence level). In Gale crater, the average iron abundance observed in VRR basaltic bedrock is equivalent to $\sim 19.5$ wt.\% $\mathrm{FeO}_{\mathrm{T}}$ from the MOC quantification method. Consequently, the LOD and $\mathrm{L}_{\mathrm{c}}$ are graphically obtained (Figure 1.a) similarly to Lasue et al., [2012] or Wiens et al., [2013], from this level of composition, using the prediction intervals of the regression curve. The interval between both boundaries of the prediction bands for a value given by the upper prediction band at the average iron abundance observed in VRR rocks gives the LOD (Figure 1.a). This method takes into account all sources of variation. The critical level $\mathrm{L}_{c}$ is defined similarly and corresponds to the range between the upper prediction interval and the regression model at a compositional level of reference. The LOD and $\mathrm{L}_{c}$ for excess iron above the iron average observed in Gale bedrock, and for individual ChemCam observation point measurements, are respectively equivalent to $\sim 7 \mathrm{wt}$. $\% \mathrm{FeO}_{\mathrm{T}}$ (equivalent to $\sim 7.8 \mathrm{wt} . \% \mathrm{Fe}_{2} \mathrm{O}_{3}$ ) and $\sim 2.5 \mathrm{wt} . \% \mathrm{FeO}_{\mathrm{T}}$ (equivalent to $\sim 2.8 \mathrm{wt} . \% \mathrm{Fe}_{2} \mathrm{O}_{3}$ ). However, these values correspond most probably to an upper limit for the $\mathrm{L}_{\mathrm{c}}$ and LOD as the model was built using a large set of mineralogical assemblages, which introduces variations in the regression curve. This ensures that the regression curve is applicable to a large suite of samples, including VRR mineralogy, but this increases the $\mathrm{L}_{\mathrm{c}}$ and LOD. Moreover, these parameters are expected to decrease as the number of rocks analyzed is increased. We conclude that the increase in hematite content should be higher than the $\mathrm{L}_{\mathrm{c}}\left(\sim 2.8\right.$ wt.\% $\left.\mathrm{Fe}_{2} \mathrm{O}_{3}\right)$ to be significantly detected with high confidence using such a method, independently of the matrix considered. This result shows that ChemCam should be able to reliably observe relatively small increases of iron oxides in martian rocks. For comparison, the combined abundances of iron oxides and iron sulfates (hematite, magnetite, akaganeite and jarosite) measured by the CheMin instrument at the Stoer (Pettegrove Point), Highfield (grey Jura) and Rock Hall (red Jura) represent increases of 12.4 wt. $\%,+4.2$ wt. $\%$, and +6.4 wt.\% (respectively) relative to the Duluth drill sample (DU, preVRR terrain).

\subsection{Martian data selection}

For martian applications, we used the same procedure currently used by the MOC quantification method for martian data [Anderson et al., 2017b]. For all new targets, the Norm1 was used to normalize the spectrum. If the iron abundance fell in the high iron range [17-100 wt. $\left.\% \mathrm{FeO}_{\mathrm{T}}\right]$, the abundance was kept. Otherwise, if the iron abundance predicted fell in the low iron range $\left[0-15 \mathrm{wt} . \% \mathrm{FeO}_{\mathrm{T}}\right]$, the method was run again normalizing the spectrum with Norm3 (see Section 3.3), and a new iron abundance was predicted. If the first prediction gave an iron abundance in the $\left[15-17\right.$ wt. $\left.\% \mathrm{FeO}_{\mathrm{T}}\right]$, the blend model was used to predict a new iron abundance considering a linear weighted sum of the two predicted $\mathrm{FeO}_{\mathrm{T}}$ abundances with Norm1 and Norm3. Empirically, for our laboratory dataset, such a procedure gives a better result than using only one method of normalization, applied to the full range of iron abundance in the samples.

Among all the ChemCam analyses acquired along with the VRR traverse and pre-VRR terrains at Blunts Point (5382 ChemCam observation points), two datasets were selected to refine the composition of dark-toned features and to monitor iron variability in the VRR bedrock. Both lists of selected targets can be found in the supplementary materials table S4, (David. 2020c).

The first dataset included the ChemCam observation points located on dark-toned features observed in the Jura member. These dark-toned diagenetic features were classified into three different groups reflecting distinct morphologies: nodular concretions near calcium sulfate veins, dark-toned fracture fills, and crystal-shaped casts in the host rocks [L'Haridon et $a l$., this issue]. This dataset (59 ChemCam observation points) was primarily selected based on 
the ChemCam RMI images combined with the first iron estimation given by the MOC method. Because laser shots can be located on the edge of dark-toned features and surrounding host rock or light-toned Ca-sulfate veins, some dilution effects are expected.

The second dataset included all the ChemCam observation points acquired in the bedrock of the three lithostratigraphic members including VRR (Pettegrove Point and Jura) and Blunts Point member. Soil and float rock targets, as well as pervasive diagenetic concretions observed along with the Murray formation [Sun et al., 2019], dark-toned features, bleached-halos, and light-toned calcium sulfate veins, were removed from that dataset in order to have the more representative targets of the sedimentary rocks. To avoid laser points that probed a mixture of bedrock and Ca-sulfate veins, we excluded all ChemCam observation points showing more than $5 \mathrm{wt} . \% \mathrm{CaO}$, in addition to the visual sorting of diagenetic features. After this data selection, $2677 \mathrm{ChemCam}$ observation points remained. The distinction between the red and grey Jura was made using the Mastcam contextual color images [Malin et al., 2017], which provide a $150 \mu \mathrm{m}$ per pixel resolution at $\sim 2$ meters.

\section{Results}

4.1 Variation of iron abundance along stratigraphy

Figure 3.a displays the results given by our refined model in martian bedrock as a function of the elevation (from sol 1697 to 2300 of the mission), for three of the Murray stratigraphic members: Blunts Point (orange dots), Pettegrove Point (blue dots) and Jura (red and grey dots). Dark-toned features and associated bleached-host rocks encountered mainly in the grey Jura member (and to a lesser extent in Pettegrove Point and red Jura as well) are also represented (squares in Figure 3.a). The highest iron abundances recorded by ChemCam along VRR traverse were encountered in the dark-toned diagenetic features (see Figure 4.a for illustration). Note that our dataset does not include iron meteorites. In Figure 3.a, all three types of dark-toned features follow the same distribution between pure iron composition and typical iron abundances observed in bedrock. Even though we selected the dark-toned features with the lowest visible contamination from the surrounding material (veins or bedrock), such a trend suggests that contamination at different levels occurs nonetheless due to the very small scale of the features. However, our new method of determining iron abundances confirmed that darktoned features with a low level of contamination have iron abundances that are very close to pure iron oxide composition.

When considering only bedrock targets without diagenetic features, the iron quantification method developed for this study gives an average iron abundance at VRR that remains overall in line with the underlying terrain (Figure 3.a). The average iron values at Blunts Point member and VRR are within statistical error of each other, with $20.2 \pm 1.5$ and $21.2 \pm 1.8$ wt.\% $\mathrm{FeO}_{\mathrm{T}}$ (Table 1).

Therefore, the higher hematite content recorded by the CheMin instrument [Rampe et $a l$., this issue] at Pettegrove Point (14.7 $\pm 0.8 \mathrm{wt} . \%$ hematite) compared to the underlying Blunts Point member ( $4.3 \pm 0.7 \mathrm{wt} . \%$ hematite $)$ is likely associated with the isochemical transformation of iron-bearing phases. Indeed, the increase in hematite abundance observed in this member should be counterbalanced by an equivalent drop of other Fe-bearing minerals. This observation is consistent with another study [Rampe et al., this issue], which observed an overall decrease in smectite phyllosilicate abundances and a lack of iron-bearing phases in the amorphous component (AmC) in Pettegrove Point compared to Blunts Point member. Such phases could be the source of iron after chemical weathering, suggesting that hematite is 
probably mostly authigenic, formed from the same iron bulk reservoir as the whole Murray. Consequently, VRR was not an area where iron was preferentially concentrated. The same conclusion was made with the MOC ChemCam quantification method [Frydenvang et al., this issue] and also by APXS [Thompson et al., this issue]. Note that the latter recorded a decreasing trend in iron going up section, which is not observed in ChemCam data; this apparent disagreement could be due to differences in the number of targets analyzed and/or in the scale of analysis of both instruments.

Interestingly, although the average iron abundances were overall similar along VRR traverse for the three members (Figure 3.a), the iron variability recorded by ChemCam in bedrock increased in the upper-half part of the ridge (from $-4175 \mathrm{~m}$ to $-4145 \mathrm{~m}$ ), mostly associated with the Jura member and the top of the Pettegrove Point member. This observation is also visible in Table 1, where the standard deviations of iron abundances for red and grey Jura bedrock are higher than Pettegrove Point and Blunts Point. This variability is not a sampling bias because there are a similar number of points acquired with ChemCam at Blunts Point, Pettegrove Point, red and grey Jura members. This higher variability is also observed in the histogram (inset in Figure 3.a) showing the iron distribution through these lithostratigraphic members. In VRR, a higher number of ChemCam observation points located in the bedrock exhibited iron abundances in the 22-27 wt. $\% \mathrm{FeO}_{\mathrm{T}}$ range are observed, compared to pre-VRR terrains. Nearly $10 \%$ of the ChemCam points (202 out of 2050) show some enrichment above $23.5 \mathrm{wt} . \% \mathrm{FeO}_{\mathrm{T}}$ in VRR. This threshold of $23.5 \mathrm{wt} . \% \mathrm{FeO}_{\mathrm{T}}$ is defined as the average iron value observed at VRR (see Table 1) plus the critical level $\left(\mathrm{L}_{\mathrm{c}}\right)$ defined for iron oxide mixtures with our quantification model. More ChemCam observation points with $\mathrm{FeO}_{\mathrm{T}}>23.5$ wt.\% were recorded in the grey Jura $(19.9 \%, 118$ out of 591 points) compared to red Jura $(5.9 \%, 39$ out of 662 points) and Pettegrove Point (5.6\%, 45 out of 797 points). For comparison, only 2\% (13 out of 627) of ChemCam observations points showed higher abundance than $23.5 \mathrm{wt} . \% \mathrm{FeO}_{\mathrm{T}}$ in the pre-VRR Blunts Point member (and 9 points of the total 13 points were localized in the same target near the base of VRR).

If the iron oxide grain size increases (to nearly the size of the laser beam diameter), it would also increase the scatter of the $\mathrm{FeO}_{\mathrm{T}}$ abundances measured with ChemCam in a raster, as coarse grains cannot be statistically hit by the laser with the same proportion of the matrix for each observation point of the raster. This could be a partial explanation for the grey Jura part, as coarse-grained grey hematite grains are thought to be present in the bedrock according to MastCam and passive ChemCam observations [Jacob et al., this issue; L'Haridon et al., this issue] as mentioned in Section 2, although these grains are probably small compared to the $350-550 \mu \mathrm{m}$ diameter of the laser beam. However, ChemCam rock analyses reveal that variability in iron content (when discarding diagenetic features) is not observed within the same ChemCam raster, but is mainly observed between different targets, sometimes within a narrow range of distance (meter to ten meters scale), even though no change in rock texture is observed among them. ChemCam observation points that show iron abundances higher than $23.5 \mathrm{wt} . \%$ $\mathrm{FeO}_{\mathrm{T}}$ are often encountered together within the same targets (considering only targets with a minimum of five points of analysis) and the iron abundance scatter in these rocks is quite low. We noticed that $66 \%$ of all the Fe-rich points $\left(>23.5 \mathrm{wt} . \% \mathrm{FeO}_{\mathrm{T}}\right)$ observed in VRR were encountered in targets with at least half of their points being Fe-rich. In other words, iron abundances are spatially coherent at the scale of ChemCam analyses (e.g., Figure 4.b), with the areas of enhanced iron abundances (maximum observed in a target $26.6 \mathrm{wt} . \% \mathrm{FeO}_{\mathrm{T}}$ with $\sigma=0.85$ ). Consequently, as the variability in iron abundance was mainly observed between different targets and to a lesser extent in the same ChemCam raster sequence, we can assume that grain size has only a second-order effect. In addition, neutron-absorbing elements (the 
main elements on Mars are Fe and $\mathrm{Cl}$, [Hardgrove et al., 2011]) measured by DAN in active mode show higher variability across the Jura member compared to Pettegrove Point and Blunts Point [Fraeman et al., this issue], indicating that our chemostratigraphic trends from target to target are qualitatively consistent with bulk-rock measurements in VRR.

Figure 3.b represents the average iron abundance per ChemCam target at VRR along the rover traverse. This map shows that Fe-enhanced areas are particularly located in the SouthSouth/West of the rover path. Local variations between rock slabs were also observed all along the traverse, as well as an enhancement in the easternmost area of the rover traverse. Sedimentary stratification within the ridge is nearly horizontal [Bennett et al., this issue; Edgar et al., this issue, Stein et al., this issue]. Consequently, the variations of iron abundances observed in VRR do not appear to be stratigraphically controlled, as lateral iron variations are observed. In VRR Fe-rich bedrock, no visible diagenetic features like nodules, concretions or vein fills were observed in the RMI context images (e.g., Figure 4.b). Moreover, areas of Feenhanced abundances in the bedrock do not show a strong correlation with areas where darktoned features were encountered (Figure 3.b), eliminating the possibility of contamination from these Fe-rich features.

\subsection{Depth profiles of Fe-rich bedrock}

Because ChemCam performs 30 shots per observation point, it is possible to study the compositional variations with depth. The laser ablation rate is usually of the order of $\sim 1 \mu \mathrm{m}$ per shot [Wiens et al., 2013; Maurice et al., 2016; Chide et al., 2019]. Figure 5 shows the shotto-shot profiles on ChemCam observation points from VRR defined as "Fe-rich points", i.e., with iron abundances higher than $23.5 \mathrm{wt} . \% \mathrm{FeO}_{\mathrm{T}}$ in bedrock (excluding diagenetic features). Some first shots in the Pettegrove Point member show higher iron abundances (up to $54 \mathrm{wt} \%$ $\mathrm{FeO}_{\mathrm{T}}$ ), probably due to the presence of coarse-grained Fe-rich phases hit by the laser beam, to high-iron dust, or to a thin high-iron layer. Only four ChemCam observation points (out of 202) show high-Fe abundances in the first shots and probably correspond to specific cases. Consequently, there is overall no chemical iron gradient with depth in the bedrock of VRR. Iron-bearing phases are probably homogeneously present as mineral grains within the rocks, rather than as a rock varnish that can occur during weathering, unless a thick coating of several tens of micrometers is present. The absence of iron rock coating in ChemCam's chemistry is consistent with passive observations that show that the rock surfaces have similar ferric spectral signatures to freshly fractured bedrock or similar to the drill tailings [Fraeman et al., this issue; Jacob et al., this issue]. Moreover, the comparison to terrestrial analogs suggests that chemical surface weathering on "modern" Mars (i.e., Amazonian) is commonly outpaced by physical erosion, preventing the development of alteration rinds on rocks [Salvatore et al., 2019].

\subsection{Major and minor element abundances in the VRR bedrock}

Correlations between chemical compounds can be used to infer the presence of specific mineral phases in ChemCam data. However, ChemCam observation points that are relatively enriched in iron do not show any positive correlation between $\mathrm{Fe}$ and other major elements (see supplementary materials Figure S2), but iron-rich points are generally associated with lower abundances of $\mathrm{Si}, \mathrm{Mg}, \mathrm{Ca}, \mathrm{Al}, \mathrm{Ti}$ and $\mathrm{Na}$ elements. 
Trace and minor elements may display greater changes in concentration than major elements. Among trace and minor elements, we selected lithium and hydrogen because they can bring clues on the nature of the Fe-rich phases. $\mathrm{Li}$ is expected to be associated with silicate or clays rather than iron oxides (Cornell et al., 2003; Marshall et al., 1998). Consequently, an increase of the $\mathrm{Li}$ abundance associated with an increase of the iron content would argue against iron oxide detection. Otherwise, $\mathrm{H}$ signal can help to constrain the hydration state of the $\mathrm{Fe}$ rich phases. First, as seen in Figure 6.a, Li abundances quantified from the $670 \mathrm{~nm}$ emission line [Payré et al., 2017] are overall lower in iron-rich ChemCam observation points. Similarly, the hydrogen abundances quantified from the Balmer alpha wavelength of $656.6 \mathrm{~nm}$, normalized to total intensity [Rapin et al., 2016], follow the same trend (Figure 6.b), with on average a weak $\mathrm{H}$ signal in the iron-enriched targets. The triangular form in the scatter of ChemCam data (observed in the Figure 6 plots) can be explained by the presence of mixtures including several major chemical phases in variable proportions. For each element $(\mathrm{H}$ and $\mathrm{Li})$, a Kolmogorov-Smirnov test (5\% of significance level) was performed to confirm that the two iron ranges $\left(<23.5\right.$ and $\left.>23.5 \mathrm{wt} . \% \mathrm{FeO}_{\mathrm{T}}\right)$ do not follow the same distribution. Lithium and hydrogen can help to constrain the nature of Fe-bearing phases in addition to major chemistry, as discussed in more detail in Section 5.1.1.

The relative abundances in major elements compared to iron can help to constrain the process responsible for iron variability observed in the VRR bedrock. Ternary plots (Figure 7) show the iron abundances in VRR rocks compared to the other major elements measured by ChemCam. In these plots, in addition to ChemCam measurements in the VRR bedrock, also included are the dark-toned diagenetic features of grey Jura as well as associated bleached light-toned halos. In Figure 7, we observe that iron content variations in the Jura bedrock follow the same trend defined by bleached halos depleted in iron (blue squares in Figure 7), darktoned features (black squares in Figure 7), and pure iron composition. Implications for such a trend between dark-toned features and bleached halos are discussed in L'Haridon et al., [this issue]. For the VRR bedrock, the trend toward pure iron composition shows that ChemCam observation points with enhanced iron abundances are not associated with variations in other elements, as they keep the same relative abundances. Some points in bedrock are trending toward the Mg end-member (especially for iron abundances near VRR average value) possibly induced, for example, by the presence of $\mathrm{Mg}$-bearing phases with higher variability in particle sizes or by Mg-rich concretions, although no such features are visible in the RMI images. Such variability in $\mathrm{Mg}$ is also observed in bleached-host rocks (blue squares in Figure 7). However, these $\mathrm{Mg}$ enrichments are not associated with an overall increase in iron abundance. For $\mathrm{Fe}-$ rich points, no depletion in mobile elements $(\mathrm{Na}, \mathrm{K}$, and $\mathrm{Ca}$ ) compared to immobile elements ( $\mathrm{Ti}, \mathrm{Al}$ or to a less extent $\mathrm{Si}$ ) is observed (Figure 7). Consequently, these observations show that in these points, iron is the only variable element among these bedrock outcrops compared to other major elements.

\section{Discussion}

5.1 Mineralogy of VRR from ChemCam and other datasets

The CheMin instrument observed some noticeable changes in the mineralogy of the three members of VRR, as previously noted in Section 2 and summarized in Table 2. This table also summarizes some ChemCam observations from the present and other studies. 


\subsubsection{Iron-oxide detections in VRR}

CheMin results at VRR show the presence of several iron-rich phases such as $\mathrm{Fe}$ bearing clays, iron oxides (hematite, akaganeite, magnetite), pyroxene and jarosite ([Rampe et al., this issue]; Table 2). All these phases, if sampled with ChemCam in greater proportion, could be responsible for the increased iron in some bedrock. However, pyroxene is unlikely to be the source of areas of enhanced iron abundances because we would expect to see some positive correlation between $\mathrm{Fe}$ and $\mathrm{Si}$ or/and $\mathrm{Mg}$ or/and $\mathrm{Ca}$ (if ferrosilite or/and enstatite or/and wollastonite are present), which is not observed (Fig. 7). ChemCam observation points have shown that Li abundance is lower in the Fe-rich areas (Section 4.3). This element is not expected to be particularly associated with iron oxides/sulfates [Cornell et al., 2003], but rather with silicates or absorbed by clay minerals during weathering [Marshall et al., 1998]. The lack of $\mathrm{H}_{2} \mathrm{O}$ releases at high temperature during the SAM evolved gas analysis (EGA) indicates that phyllosilicates in VRR are consistent with dioctahedral Fe-rich smectite [McAdam et al., this issue]. However, the decrease in hydrogen abundance in Fe-rich points is inconsistent with the presence of hydrous iron-bearing phyllosilicates such as smectite. This would suggest that the Fe-rich points observed by ChemCam could correspond to Fe-oxides or sulfates instead of Ferich clays. Finally, increased iron content is not associated with elements like phosphorus or sulfur, which makes the presence of iron sulfates and iron phosphates unlikely. The lack of a positive correlation between $\mathrm{Fe}$ and $\mathrm{K}$ could suggest that jarosite (which can contain up to 9 wt. $\% \mathrm{~K}_{2} \mathrm{O}$, depending on the $\mathrm{K} / \mathrm{Na}$ ratio) is probably not responsible for the entire increase in iron abondance, although the low abundance of this mineral phase in VRR [Rampe et al., this issue] and mixing with other Fe-rich phases could make it difficult to detect with ChemCam. Our study shows that the increase in iron abundance in some VRR bedrock is not associated with relative variation in other elements (see Section 4.3, Figure 7). Consequently, all these observations indicate that ChemCam observation points with higher iron abundances correspond mainly to the addition of iron oxides.

Interestingly, hematite is by far the major Fe-bearing phase in the Pettegrove Point member (Table 2). The mass balance calculations using both CheMin and APXS data suggest that the amorphous components of the VRR samples are Fe-poor compared to their crystalline counterparts, especially at Stoer [Rampe et al., this issue]. Consequently, ChemCam observations with higher iron contents in the Pettegrove Point and Jura members are best explained by an increase in the abundance of one or more Fe-rich crystalline phases (primarily hematite, according to XRD results) rather than by an increase in the abundance of the amorphous component. The drop in hydrogen abundances recorded in ChemCam observation points with high iron abundances is attributed to the enhanced sampling of anhydrous iron oxides that is consistent with hematite (rather than akaganeite or jarosite).

\subsubsection{Chlorine observations in VRR}

In red Jura, the major iron oxide mineral observed by CheMin is akaganeite (Table 2) followed by hematite. ChemCam is only sensitive to chemistry and not directly to mineralogy, and therefore the contribution from each Fe-bearing mineral in the LIBS iron signal cannot be discriminated. However, because akaganeite is a Cl-bearing iron hydroxide, the LIBS chlorine signal can be useful to track the presence of this mineral. Relative chlorine abundances are estimated from the $837.8 \mathrm{~nm}$ peak area. In order to avoid any contribution from possible halite detections, Na-rich points have been removed $\left(\mathrm{Na}_{2} \mathrm{O}>3.5\right.$ wt.\%). Nevertheless, no obvious correlation between $\mathrm{Fe}$ and $\mathrm{Cl}$ has been observed in the red Jura data points. Moreover, the $\mathrm{Cl}$ signal observed in red Jura bedrock (excluding the Rock Hall drill data points) is only slightly higher than that of the other VRR locations. On the other hand, the $\mathrm{Cl}$ signal is clearly higher 
in the Rock Hall drill location (where CheMin recorded the highest concentration of akaganeite), compared to the rest of the red Jura member (Figure 8). This difference is significant as the first quartile of the Rock Hall drill location data is above the third quartile of the red Jura data (without ChemCam observation points located in the Rock Hall drill location). This could also be consistent with active neutron data from the DAN instrument, which is sensitive to $\mathrm{Fe}, \mathrm{Cl}$ and $\mathrm{H}$ at $\sim 60 \mathrm{~cm}$ depth in a $\sim 3 \mathrm{~m}$ surface footprint (e.g., [Litvak et al., 2008]). Using the method of Gabriel et al., [2018] at the Rock Hall location, active DAN analysis indicates a significant enrichment in $\mathrm{Cl}$ or/and $\mathrm{Fe}$ in the bulk rock near the drill site [Fraeman et al., this issue]. Fe-rich observation points in ChemCam data are not associated with a strong $\mathrm{H}$ signal, which supports the idea that anhydrous iron oxide (like hematite) could be present predominantly relative to hydrous iron oxides (e.g., akaganeite and jarosite) as seen in Section 4.3. These observations indicate that the amount of akaganeite given by CheMin analysis of Rock Hall likely represents an upper limit for VRR, or that akaganeite with a lower amount of $\mathrm{Cl}$ is present in the rest of VRR. Rock Hall not being fully representative of the entire red Jura is also supported by the higher $\mathrm{SiO}_{2}$ abundances recorded from ChemCam at the drill location, as well as the sudden rise of the chemical index of alteration at this location [Frydenvang et al., this issue]. These observations suggest that akaganeite could be present in highly variable proportions throughout this member.

\subsubsection{Iron abundances in dark-toned features}

The dark-toned diagenetic features are present mostly in the grey Jura member and exhibit an Fe abundance close to pure iron oxide composition. This result is consistent with other observations made in L'Haridon et al., [this issue], who report the lack of element detection like phosphorous, fluorine, carbon, chlorine or sulfur in dark-toned features. The absence of these elements argues in favor of iron oxide minerals rather than iron-sulfate or iron phosphate. Our quantification model has an RMSE equivalent to $\sim 7 \mathrm{wt} . \% \mathrm{FeO}_{\mathrm{T}}$ for reference samples with $>80 \mathrm{wt} . \% \mathrm{FeO}_{\text {T. }}$ Considering such uncertainty, the highest iron abundance given by our model in dark-toned features $\left(98 \mathrm{wt} . \% \mathrm{FeO}_{\mathrm{T}}\right)$, likely corresponds to the target with the least contamination from surrounding materials and is consistent with anhydrous iron oxide (e.g., hematite or magnetite), and inconsistent with iron-sulfate or iron phosphate. L'Haridon et al., [this issue] observed that the $\mathrm{H}$ signal is not particularly elevated in dark-toned concretions, and therefore the presence of iron hydroxides like goethite, lepidocrocite or ferrihydrite is rather unlikely. The flat passive spectra of dark-toned features suggest the presence of opaque minerals such as grey hematite or mixed-valence Fe-oxide like magnetite [L'Haridon et al., this issue]. As the oxygen signal in LIBS spectra is mainly controlled by the atmospheric contribution, it is difficult to decipher the oxidation number of these iron oxides phases. However, the hexagonal habit and distribution of angles (median $\sim 120^{\circ}$ ) observed on some dark-toned crystals are consistent with crystalline grey hematite, preferentially to any other iron oxides [L'Haridon et al., this issue].

5.2 Processes responsible for enhanced iron abundances observed by ChemCam in the VRR bedrock

Chemical sedimentary rock compositions are influenced by several factors including variations in the source of sediments [Harrold and Moore, 1975; Girty et al., 1988; Johnsson et al., 1990 Cousin et al., 2017]; differences in the degree of chemical weathering (e.g., variation in the water-rock reaction) during transport and deposition [Suttner et al., 1981; Mangold et al., 2019]; physical sorting [Johnsson et al., 1991]; original depositional setting (e.g., $\mathrm{pH}$ and redox conditions) and diagenetic processes [Boles, 1984; Bjørlykke et al., 1992; Hurowitz et al., 2017]. For sedimentation in a lake with a stable level, as proposed for VRR 
[Fedo et al., 2019], all these processes can induce a variation of the chemical composition of sedimentary rocks. Excluding diagenesis (with fluid flow disconnected from the lake water), such processes are expected to produce iron variations that would be consistent with stratigraphy. However, the iron variations observed in VRR do not appear to be entirely stratigraphically controlled, since lateral variations of iron content are observed (Figure 3.b). Consequently, even though some of the Fe-bearing phases could be authigenic and precipitated from the lake, or iron-rich sedimentary input, some diagenetic processes including groundwater circulation, are required to produce such iron variations. Indeed, during diagenesis, the total iron abundance of the sediments could change (increase or decrease), or iron could change its valence state, which controls its mobility (e.g., [Mücke et al., 1994; Vigliotti et al., 1999; Bowen et al., 2008]). The increase in iron abundance variability among rocks of the upper VRR part could indicate that this area of the ridge underwent more extensive alteration and/or with different fluid conditions.

Our study shows that the increase in iron abundance in some VRR bedrock is not associated with relative variation in other elements as they keep the same relative abundances (see Section 4.3, Figure 7). This observation argues against the scenario where the increase in iron abundances in bedrock is controlled by passive enrichment during chemical weathering. Indeed, differential leaching zones where soluble elements are drained by fluids during weathering leading to a relative enrichment of immobile elements such as $\mathrm{Fe}^{3+}$ (similarly to iron laterite formation process on Earth (e.g., [Schellmann, 1994]), is not a relevant hypothesis for the source of iron variability observed in VRR rocks. In such a case, Fe-rich rocks are expected to also show passive enrichment in other insoluble elements like $\mathrm{Ti}, \mathrm{Al}$ or to a less extent $\mathrm{Si}$, compared to more mobile elements (like $\mathrm{Ca}, \mathrm{Mg}, \mathrm{K}$ or $\mathrm{Na}$ ), which is not observed here. Furthermore, iron mobility driven by fluctuations in acidity conditions should show a similar trend, with depletion in mobile elements. However, $\mathrm{Na}, \mathrm{K}, \mathrm{Ca}$ and $\mathrm{Mg}$ elements do not show any decrease relative to $\mathrm{Ti}$ or $\mathrm{Al}$ in Fe rich rocks (see Section 4.3 Figure 7). Consequently, this observation argues in favor of iron abundance variability being mostly driven by redox processes that only affect redox-sensitive elements such as iron. The variability in iron abundance observed in the bedrock highlighted by our study potentially originates from a redox process similar to the process that formed the dark-toned features and bleached halos (see L'Haridon et al., [this issue] for details about the formation of the dark-toned features), but at the scale of the whole member.

\subsection{Possible scenario responsible for the mobility of iron}

Because the iron variability seen in ChemCam data is mainly observed in the upper part of the ridge, the redox process involved in the iron mobility is probably related to the alteration episode that formed the Jura member. Due to the higher proportion of Fe-rich ChemCam observation points in the grey Jura bedrock (19.9\% compared to 5.6\% in the red Jura - see Section 4.1), we conclude that some iron mobility took place during the alteration of this member. However, we have no ability to determine whether the iron variability observed in red Jura is associated with the same event with limited fluid percolation into this member, or if it was associated with a distinct diagenetic episode. Consequently, both possibilities are considered.

In both scenarios, the source of ferric iron could be provided by local source remobilization from igneous minerals, iron oxide minerals such as hematite (or its precursors), and iron phases present in the amorphous component (e.g., Np-Ox/ferrihydrite or hisingerite [Dehouck et al., 2014, 2017]). Indeed, amorphous phases such as ferrihydrite dissolve much 
faster than goethite or hematite [Cornell et al., 1974] due to their poorly ordered and nanoparticulate nature [Schwertmann et al., 1999].

The red Jura member location sampled by CheMin is characterized by the presence of higher anhydrite content combined with akaganeite and acidic-mineral such as jarosite [Rampe et al., this issue], in addition to hematite (Table. 2), which suggests that this member - or at least this location - underwent a diagenetic event involving an acidic saline brine. The variable proportions of $\mathrm{Cl}$, suggestive of akaganeite observed in red Jura seen by ChemCam (Section 5.1.2) could suggest that the fluid flow was perhaps not pervasive but patchy or that akagaenite was destabilized afterward during fluid circulation events. Our study shows that iron enrichment in some rocks is most likely induced by changes in redox conditions, as iron is preferentially mobilized compared to other major elements. Indeed, temporal and spatial gradients in Eh may drive diffusive mass transfer and reactions that could precipitate and accumulate iron oxides via abiotic means [Chan et al., 2004, 2005]. Ferric iron could be reduced to $\mathrm{Fe}^{2+}$ ions in slightly reducing media (also suggested in Frydenvang et al., [this issue]), which allows iron mobility towards areas of preferential re-crystallization as ferric minerals like hematite, akaganeite and jarosite (Figure 9.b). Both Jura drill samples were identified as possibly containing sulfide minerals by EGA analyses [Wong et al., this issue], unlike the underlying Pettegrove Point member. This is consistent with the presence of reducing alteration fluids, although such minerals could be also primary.

Precipitation and accumulation of iron oxides in preferential areas imply an additional source of oxidant species in the diagenetic fluids, the nature of which remains unclear. Dissolution of chlorate $\left(\mathrm{ClO}_{3}{ }^{-}\right)$salts into the reducing solution could be an important iron oxidant for the production of $\mathrm{Fe}^{3+}$ oxides/sulfates in localized areas. Oxychlorine species were recorded in the red Jura [McAdam et al., this issue] and were not observed since the Buckskin drill sample at the Marias Pass, lower in the Mount Sharp sequence ( $250 \mathrm{~m}$ of stratigraphy below VRR). Actually, chlorate and sulfate in solution with dissolved $\mathrm{Fe}^{2+}$ would produce goethite and/or lepidocrocite as well as akaganeite and jarosite (both observed in Jura member) in a wide range of $\mathrm{pH}$ [Mitra and Catalano, 2019]. The possible preservation of apatite minerals in the red Jura [Rampe et al., this issue; Forni et al., 2019], which are unstable in acidic media probably implies that the fluid flow event was not long-lived and/or was highly localized in its effect. Goethite and lepidocrocite hydroxide minerals produced during such reactions could be the precursors of hematite mineral observed currently following dehydration [Guo and Barnard, 2013]. Alternatively, the supply of oxidant species could be carried by another fluid. Indeed, the confluence and mixing of reducing $\mathrm{Fe}^{2+}$-bearing fluid with an oxidizing fluid could also lead to the re-precipitation of iron as ferric iron oxides (Figure 9.b). A similar process can be observed on Earth, in the Navajo sandstone [Chan et al., 2004], although the VRR bedrock is mainly composed of mudstone and consequently is probably less permeable than the terrestrial case.

Frydenvang et al., [this issue] observed a decrease of Mn abundances in the Jura member compared to the upper part of the Pettegrove Point member, in which the Mn content appears uncommonly high compared to the rest of the Murray formation. Because $\mathrm{Mn}$ is also a redox-sensitive element, such a difference in the two members of VRR may be related to the circulation of reducing fluids. Such fluids would be able to remobilize Mn from Jura bedrock. Slight changes in the $\mathrm{pH}$ and/or Eh conditions of the fluids during transport could have triggered the re-precipitation of $\mathrm{Mn}$ in the upper part of Pettegrove Point, located bellow the Jura member, as proposed by Frydenvang et al., [this issue]. This hypothesis is consistent with our observations of the presence of fluids that spatially change in redox conditions. Because 
Fe-oxides need lower potential oxidants and/or lower $\mathrm{pH}$ conditions than Mn-oxides to form, iron minerals' redistribution could be limited to the Jura members, whereas $\mathrm{Mn}^{2+}$ would remain in a soluble state and would be leached mainly toward the Pettegrove Point member. The small amount of akaganeite and jarosite recorded in the Stoer drill location in the Pettegrove Point member could indicate that these fluids percolated through this member as well but to a limited extent, due potentially to its lower permeability [Horgan et al., this issue], or that the $\mathrm{Fe}^{2+}$ : $\mathrm{ClO}_{3}{ }^{-}$and $\mathrm{Fe}^{2+}: \mathrm{SO}_{4}{ }^{2-}$ ratios increased leading to mostly precipitated $\mathrm{Fe}$-hydroxides and/or $\mathrm{Fe}-$ oxyhydroxides (rather than Fe-hydroxychlorides or Fe-hydroxysulfates), which finally transform to anhydrous iron oxides with time.

The mineralogical assemblage observed in the grey Jura indicates a different geological history than the red Jura member, with the absence of akaganeite and jarosite minerals in favor of grey hematite [Rampe et al., this issue]. Moreover, some evaporitic minerals have been replaced and filled by dark-toned materials [L'Haridon et al., this issue] in the grey Jura and not in the red one. This suggests that diagenesis ceased in the red Jura before it ceased in the grey Jura. The Mn abundances recorded by ChemCam show a decreasing trend across the 3 members [Frydenvang et al., this issue] that could reflect a different degree of alteration. A second diagenetic event has been proposed to be responsible for the lateral red-to-grey color gradient by dissolution-reprecipitation processes of akaganeite and jarosite by diagenetic fluids into grey hematite [L'Haridon et al., this issue]. The variability of iron abundance in the bedrock highlighted by our study could be related to this event. Indeed, such a hypothesis is not incompatible with our proposed scenario involving slightly reducing fluids to explain the iron mobility. From our observations, slightly reducing fluids are most likely required to transport some iron $\left(\mathrm{Fe}^{2+}\right)$, and oxidizing fluids to accumulate iron oxides in some areas. Indeed, as the fluids dissolve iron oxides, they become less and less reducing. Then the iron mobilized from the host rock by diagenetic fluids could have reprecipitated in bedrock if the fluids became locally sufficiently oxidizing (Figure 9.c). However, similarly to red Jura, the source of oxidant remains largely unconstrained. Oxidation and precipitation of $\mathrm{Mn}$, apparently from groundwater, has been observed earlier [Lanza et al., 2016], in which case the source of oxidation was also unknown.

Given enough time and sufficient pore volume, coarsening processes of grey hematite could have occurred in these fluids e.g., by Ostwald ripening, which could explain the dispersed grey hematite in the bedrock. Ostwald ripening implies the dissolution of smaller solid grains to the advantage of larger ones, due to the higher surface area (given that particle solubility is size dependent) and molecular diffusion through the liquid phase induced by chemical gradient [Cornell \& Schwertmann, 2003]. Similar processes have been proposed to explain the large hematite deposits in Meridiani Planum and Aram Chaos, although the iron mobility and deposition, in that case could be triggered by differences in $\mathrm{pH}$ and/or Eh [Ormö et al., 2004; Hurowitz et al., 2010]. At low temperature, nanoparticulate hematite is not the first iron oxide to form because it is thermodynamically metastable relative to nano-oxyhydroxides such as ferrihydrite or goethite [Guo and Barnard, 2011, 2013]. Consequently, if no relict hematite minerals were already present, the formation of grey hematite probably involved an initial precursor that transformed into hematite (by dehydration and internal rearrangement) when the crystal dimension reached a critical size [Guo and Barnard, 2011, 2013]. Alternatively, Egglseder et al., [2018] proposed a model for the Banded iron formations (BIFs) on Earth, which could be relevant to explain the hematite coarsening processes observed in the VRR bedrock. In their model, during diagenesis, dissolution of minerals encapsulated hematite grains leads to their accumulation and aggregation by non-classical crystallization, i.e., by oriented attachment [Penn and Bandfield, 1998]. 
Assuming that only one diagenetic episode is responsible for all of the iron variability observed at VRR, it would potentially imply that hematite coarsening also occurred in the red Jura and Pettegrove Point as well but to a more limited extent, as also suggested by the restricted observations of dark-toned features. Limited groundwater interaction in red Jura and Pettegrove Point rocks could be consistent with a less developed coarsening effect, which prevents significant spectral properties change of the rocks due to a lower abundance of opaque grey hematite.

\section{Conclusions}

Due to its rapid remote-sensing method of acquisition, during the VRR campaign, ChemCam acquired LIBS spectra from 3902 observation points that provide a statistically significant survey of the bedrock chemistry along the ridge. In addition to monitoring the chemostratigraphy, the submillimeter $(350-550 \mu \mathrm{m})$ diameter of the ChemCam laser beam enables it to probe to very fine features such as mineral phases or diagenetic concretions.

In this work, we first refined the ChemCam iron calibration with new Fe-rich samples in order to increase the sensibility of the ChemCam iron quantification for small variations of iron and to provide improved accuracy for iron-rich measurements such as iron oxides. The attempt for a refined calibration confirmed the validity of the method used for the archived data (MOC, [Clegg et al., 2017]) typically up to $\sim 23 \mathrm{wt} . \% \mathrm{FeO}_{\mathrm{T}}$. Our model allows us to include in the analysis a few Fe-rich bedrock points, and support the analysis of very high-Fe data.

Our results show that the iron abundance of diagenetic concretions (referred to as darktoned features in this paper), encountered at several locations on VRR, is close to pure anhydrous iron oxide, which is consistent with other work [L'Haridon et al., this issue].

In the VRR bedrock, the average iron abundance remains overall in line with the underlying stratigraphic unit at Blunts Point, as also observed with the APXS instrument [Thompson et al., this issue]. This suggests that the higher hematite content recorded by the CheMin instrument [Rampe et al., this issue] at Pettegrove Point (14.7 $\pm 0.8 \mathrm{wt} . \%$ hematite) compared to the underlying Blunts Point member ( $4.3 \pm 0.7 \mathrm{wt} . \%$ hematite $)$ is mostly associated with the isochemical transformation of iron-bearing phases.

Although the average iron content is generally similar to underlying stratigraphic unit, ChemCam recorded a higher variability in the upper part of the ridge, mainly associated with the Jura member and the upper part of the Pettegrove Point member, which is attributed to a change in the bulk iron content of the rocks, and not to grain size effects. In-depth chemical study of these Fe-rich bedrock with other major elements show that the enhanced iron abundance is most likely associated with the addition of anhydrous iron oxides such as hematite. CheMin recorded the minerals akaganeite $\left(\mathrm{Fe}^{3+} \mathrm{O}(\mathrm{OH}, \mathrm{Cl})\right)$ as the major Fe-bearing phase in red Jura. However, ChemCam data show that the $\mathrm{Cl}$ signal is particularly high in the drill sample location only, and not in the other rocks of red Jura. This indicates that akaganeite formation could be spatially heterogeneous and that the amount of the mineral given by CheMin analysis likely represents an upper limit for VRR.

Given that the locations of areas of enhanced iron abundance in VRR do not conform to the stratigraphy, we conclude that diagenetic fluids are involved. In Fe-rich bedrock, mobile elements do not show any depletion compared to insoluble elements, which argues against passive enrichment during chemical weathering. Also, iron mobility driven by acidity should show a similar trend with depletion in mobile elements. Consequently, Eh variations of the 
fluids are likely the source of iron mobility and accumulation. Except under highly acidic conditions, iron is only soluble in its ferrous state $\left(\mathrm{Fe}^{2+}\right)$, which suggests a reducing fluid was involved in its transport. Reducing conditions are also involved to explain the preferential mobility of manganese (that is also a redox-sensitive element) from the Jura member into the upper Pettegrove Point member as suggested by Frydenvang et al., [this issue]. In our study, we hypothesized that areas of enhanced iron are most probably due to the increase of the Eh conditions of the fluids that lead to the accumulation of iron oxides. This scenario implies the addition of oxidant species into the fluids. Although the source of oxidant remains largely unconstrained, we propose chlorates as a possible candidate for $\mathrm{Fe}^{2+}$ oxidation due to its occurrence in red Jura [McAdam et al., this issue], and the detection of akaganeite minerals expected from such reaction [Mitra et al., 2019], observed in both Pettegrove Point and red Jura.

\section{Acknowledgments}

We are grateful to the MSL science and operation teams who developed the rover and collected data. Funding for the ChemCam instrument and operations was provided by the NASA Mars Exploration Program in the United States and by the Centre National d'Etude Spatiales (CNES) and the Centre National de la Recherche Scientifique (CNRS) in France. All the ChemCam data used in this paper are released and can be found on the Planetary Data System (https://pdsgeosciences,wustl.edu/missions/msl/index.htm). Laboratory LIBS experiments were conducted at the Institut de Recherche en Astrophysique et Planétologie (IRAP), Toulouse, France, and at the Los Alamos National Laboratory (LANL), USA and data can be found respectively in David (2020a, 2020b). Informations about laboratory samples and VRR targets can be in the supplementary tables and are also available from David (2020c).

\section{References}

Allen, C. C., Jager, K. M., Morris, R. V., Lindstrom, D. J., Lindstrom, M. M., \& Lockwood, J. P. (1998). Martian regolith simulant JSC Mars-1. 29th Lunar Planet. Sci. Conf., Abstract \#1690.

Anderson, D. E., Ehlmann, B. L., Forni, O., Clegg, S. M., Cousin, A., Thomas, N. H., et al. (2017a). Characterization of LIBS emission lines for the identification of chlorides, carbonates, and sulfates in salt/basalt mixtures for the application to MSL ChemCam data. Journal of Geophysical Research: Planets, 122(4), 744-770.

Anderson, R. B., Clegg, S. M., Frydenvang, J., Wiens, R. C., McLennan, S., Morris, R. V., et al. (2017b). Improved accuracy in quantitative laser-induced breakdown spectroscopy using sub-models. Spectrochimica Acta Part B: Atomic Spectroscopy, 129, 49-57. https://doi.org/10.1016/j.sab.2016.12.002

Bennett, K. A., Rivera-Hernandez, F., Tinker, C., Horgan, B., Fey, D. M., Edwards, C., et al. Extensive diagenesis revealed by fine-scale features at Vera Rubin ridge, Gale crater, Mars. Journal of Geophysical Research: Planets, 2019JE006311

Barrón, V. \& Torrent, J. (2002). Evidence for a simple pathway to maghemite in Earth and Mars soils. Geochimica et Cosmochimica Acta, 66(15), 2801-2806.

Bjørlykke, K., Nedkvitne, T., Ramn, M., and Saigal, G. C. (1992). Diagenetic processes in the Brent group (Middle Jurassic) reservoirs of the North Sea: an overview. Geological Society, London, 61, 263-287.

Blake, D., Vaniman, D., Achilles, C., Anderson, R., Bish, D., Bristow, T., et al. (2012). Characterization and Calibration of the CheMin Mineralogical Instrument on Mars Science Laboratory. Space Science Reviews, 170(1), 341-399. 
https://doi.org/10.1007/s11214-012-9905-1

Boles, J. R. (1984). Secondary porosity reaction in the Stevens Sandstone, San Joaquim Valley, California: Part 2. Aspects of porosity modification. AAPG special volumes, 37, $217-$ 224.

Bowen, B. B., Benison, K. C., Oboh-Ikuenobe, F. E., Story, S., \& Mormile, M. R. (2008). Active hematite concretion formation in modern acid saline lake sediments, Lake Brown, Western Australia. Earth and Planetary Science Letter, 268, 52-63.

Bridges, J. C., Catling, D. C., Saxton, J. M., Swindle, T. D., Lyon, I. C., \& Grady, M. M. (2001). Alteration Assemblages in Martian Meteorites : Implications for Near-Surface Processes. Space Science Reviews, 96(1), 365-392. https://doi.org/10.1023/A:1011965826553

Burns, R. G., \& Fisher, D. S. (1990). Iron-sulfur mineralogy of Mars: Magmatic evolution and chemical weathering products. Journal of Geophysical Research, 95, 14415-14.

Catling, D. C., \& Moore, J. M. (2003). The nature of coarse-grained crystalline hematite and its implications for the early environment of Mars. Icarus, 165(2), 277-300. http://dx.doi.org/10.1016/S0019-1035(03)00173-8.

Campbell, J. L., Perrett, G. M., Gellert, R., Andrushenko, S. M., Boyd, N. I., Maxwell, J. A., et al. (2012). Calibration of the Mars Science Laboratory Alpha Particle X-ray Spectrometer. Space Science Reviews, 170(1), 319-340. https://doi.org/10.1007/s11214-012-9873-5

Cardoso, J. F., \& Souloumiac, T. A. (1993). Blind Beamforming for Non Gaussian Signals. IEEE Proceedings $F$ - Radar and Signal Processing, 140(6), 362 - 370.

Cardoso, J. F. (1997). Infomax and maximum likelihood for blind source separation. IEEE Signal Processing Letters, 4(4), 112-114. https://doi.org/10.1109/97.566704

Chan, M., Bowen, B., Parry, W., Ormö, J., \& Komatsu, G. (2004). A possible terrestrial analogue for hematite concretions on Mars. Nature, 429, 731-734. https://doi.org/10.1038/nature02600

Chan, M. A., Bowen, B. B., Parry, W. T., Ormö, J., \& Komatsu, G. (2005). Red rock and red planet diagenesis : Comparisons of Earth and Mars concretions. GSA TODAY, 15(8).

Chide, B., Maurice, S., Murdoch, N., Lasue, J., Bousquet, B., Jacob, X., et al. (2019). Listening to laser sparks: A link between Laser-Induced Breakdown Spectroscopy, acoustic measurements and crater morphology. Spectrochimica Acta Part B: Atomic Spectroscopy, 153, 50-60. https://doi.org/10.1016/j.sab.2019.01.008

Christensen, P. R., Bandfield, J. L., Clark, R. N., Edgett, K. S., Hamilton, V. E., Hoefen, T., et al. (2000). Detection of crystalline hematite mineralization on Mars by the Thermal Emission Spectrometer: Evidence for near-surface water. Journal of Geophysical Research: Planets, 105(E4), 9623-9642. https://doi.org/10.1029/1999JE001093

Christensen, P. R., Bandfield, J. L., Hamilton, V. E., Ruff, S. W., Kieffer, H. H., Titus, T. N., et al. (2001). Mars Global Surveyor Thermal Emission Spectrometer experiment: Investigation description and surface science results. Journal of Geophysical Research: Planets, 106(E10), 23823-23871. https://doi.org/10.1029/2000JE001370

Clegg, S. M., Sklute, E., Dyar, M. D., Barefield, J. E., \& Wiens, R. C. (2009). Multivariate analysis of remote laser-induced breakdown spectroscopy spectra using partial least squares, principal component analysis, and related techniques. Spectrochimica Acta Part B: Atomic Spectroscopy, 64(1), 79-88. https://doi.org/10.1016/j.sab.2008.10.045

Clegg, S. M., Wiens, R. C., Anderson, R., Forni, O., Frydenvang, J., Lasue, J., et al. (2017). Recalibration of the Mars Science Laboratory ChemCam instrument with an expanded geochemical database. Spectrochimica Acta Part B: Atomic Spectroscopy, 129, 64-85. https://doi.org/10.1016/j.sab.2016.12.003

Colao, F., Fantoni, R., Lazic, V., \& Paolini, A. (2004). LIBS application for analyses of martian 
crust analogues: Search for the optimal experimental parameters in air and $\mathrm{CO} 2$ atmosphere. Applied Physics A, 79(1), 143-152. https://doi.org/10.1007/s00339-0032262-X

Cornell, R.M., Posner, A. M., \& Quirk, J. P. (1974). Crystal morphology and the dissolution of goethite. Journal of Inoraganic and Nuclear Chemistry, 36(9), 1937-1946.

Cornell, R. M., \& Schwertmann, U. (2003). The Iron Oxides : Structure, Properties, Reactions, Occurrences and Uses. John Wiley \& Sons.

Cousin, A., Forni, O., Maurice, S., Gasnault, O., Fabre, C., Sautter, V., et al. (2011). Laser induced breakdown spectroscopy library for the Martian environment. Spectrochimica Acta Part B: Atomic Spectroscopy, 66(11-12), 805-814. https://doi.org/10.1016/j.sab.2011.10.004

Cousin, A., Sautter, V., Payré, V., Forni, O., Mangold, N., Gasnault, O., et al. (2017). Classification of igneous rocks analyzed by ChemCam at Gale crater, Mars. Icarus, 288, 265-283. https://doi.org/10.1016/j.icarus.2017.01.014

Curie, L. A. (1968). Limits of qualitative detection and quantitative determination. Application to radiochemistry. Analytical Chemistry, 40(3), 586-593. https://doi.org/10.1021/ac60259a007

David, G. (2020a). LIBS laboratory spectra IRAP. http://doi.org/10.5281/zenodo.3772349

David, G. (2020b). LIBS laboratory spectra LANL [dataset]. Zenodo. http://doi.org/10.5281/zenodo.3902232

David, G. (2020c). Fe quantification model, samples informations - VRR targets [dataset]. Zenodo. http://doi.org/10.5281/zenodo.3903074

Dehouck, E., McLennan, S. M., Meslin, P. Y., \& Cousin, A. (2014). Constraints on abundance, composition, and nature of X-ray amorphous components of soils and rocks at Gale crater, Mars. Journal of Geophysical Research : Planets, 119(12), 2640-2657.

Dehouck, E., McLennan, S. M., Sklute, E. C., \& Dyar, M. D. (2017). Stability and fate of ferrihydrite during episodes of water/rock interactions on early Mars : An experimental approach. Journal of Geophysical Research : Planets, 122(2), 358-382.

Le Deit, L., Hauber, E., Fueten, F., Pondrelli, M., Rossi, A. P., \& Jaumann, R. (2013). Sequence of infilling events in Gale Crater, Mars : Results from morphology, stratigraphy, and mineralogy. Journal of Geophysical Research: Planets, 118(12), 2439-2473. https://doi.org/10.1002/2012JE004322

Desrousseaux, A., Doukhan, J. C., Fieni, C., Perron, C., Jeannot, J. P., \& Lavielle, B. (1996). A New Iron Meteorite from France. Meteoritics \& Planetary Science, 31, 36.

Edgar, L. A., Fraeman, A. A., Gupta, S., Fedo, C., Grotzinger, J. P., Stack, K., et al. (2018). A Lacustrine Environment Recorded at Vera Rubin Ridge: Overview of the Sedimentology and Stratigraphy observed by the Mars Science Laboratory Curiosity Rover. American Geophysical Union, Fall Meeting 2018, abstract \#P41A-01

Edgar, L. A., Fraeman, A. A., Fedo, C. M., Gupta, S., Banham, S. G., Grotzinger, J. P., et al. A lacustrine paleoenvironment recorded at Vera Rubin ridge, Gale crater: Overview of the sedimentology and stratigraphy observed by the Mars Science Laboratory Curiosity rover. Journal of Geophysical Research: Planets, 2019JE006307RR

Effenberger, A. J., \& Scott, J. R. (2010). Effect of Atmospheric Conditions on LIBS Spectra. Sensors (Basel, Switzerland), 10(5), 4907-4925. https://doi.org/10.3390/s100504907

Egglseder, M.S., Cruden, A.R., Tomkins, A. G., Wilson, S. A., \& Langendam, A. D. (2018). Colloidal origin of microbands in banded iron formations. Geochemical perspectives letters, 6, 43-49. doi: 10.7185/geochemlet.1808

Evans, D. L., \& Adams, J. B. (1979). Comparison of Viking Lander multispectral images and laboratory reflectance spectra of terrestrial samples. 10th Lunar Planet. Sci. Conf., $1829-1834$. 
Fedo, C. M., Grotzinger, J. P., Gupta, S., Banham, S., Bennett, K., Edgar, L., et al. (2019). Evidence for persistent, water-rich, lacustrine deposition preserved in the Murray formation, Gate crater: a depositional system suitable for substained habitability. Ninth International Conference on Mars, Abstract \#6308.

Fish, F. F. (1966). The stability of goethite on Mars. Journal of Geophysical Research, 71(12), 3063-3068. https://doi.org/10.1029/JZ071i012p03063

Forni, O., Gaft, M., Clegg, S. M., Maurice, S., Wiens, R. C., Gasnault, O., et al. (2015). First detection of fluorine on Mars: Implications for Gale Crater's geochemistry. Geophysical Research Letters, 42(4), 1020-1028

Forni, O., Maurice, S., Gasnault, O., Wiens, R. C., Cousin, A., Clegg, S. M., et al. (2013). Independent component analysis classification of laser induced breakdown spectroscopy spectra. Spectrochimica Acta Part B: Atomic Spectroscopy, 86, 31-41. https://doi.org/10.1016/j.sab.2013.05.003

Forni, O., Meslin, P.Y., Cousin, A., Clegg, S. M., Mangold, N., Le Deit, L., et al. (2019). Fluorine on Mars: seven years of detection with ChemCam on-board MSL. Ninth International Conference on Mars, Abstract \#6095.

Harrold, P. J., and Moore, J. C. (1975). Composition of deep-sea sands from marginal basins of the Northwestern Pacific. Initial Reports of the Deep Sea Drilling Project, 31, 507514.

Fraeman, A. A., Arvidson, R. E., Catalano, J. G., Grotzinger, J. P., Morris, R. V., Murchie, S. L., et al. (2013). A hematite-bearing layer in Gale Crater, Mars: Mapping and implications for past aqueous conditions. Geology, 41(10), 1103-1106. https://doi.org/10.1130/G34613.1

Fraeman, A. A., Ehlmann, B. L., Arvidson, R. E., Edwards, C. S., Grotzinger, J. P., Milliken, R. E., et al. (2016). The stratigraphy and evolution of lower Mount Sharp from spectral, morphological, and thermophysical orbital data sets. Journal of Geophysical Research. Planets, 121(9), 1713-1736. https://doi.org/10.1002/2016JE005095

Fraeman, A. A., Edgar, L. A., Grotzinger, J. P., Vasavada, A. R., Johnson, J. R., Wellington, D. F., et al. (2018). Curiosity's investigation at Vera Rubin ridge. 49th Lunar Planet. Sci. Conf., Abstract \#1557.

Fraeman, A. A., Johnson, R. E., Arvidson, M. S., Wellington, R. V., Morris, V. K., Fox, B. H., et al. (a). Synergistic ground and orbital observations of iron oxides on Mt. Sharp and Vera Rubin ridge. Journal of Geophysical Research: Planets, 2019JE006294RRR

Fraeman, A. A., Edgar, L. A., Rampe, E. B., Thompson, L. M., Frydenvang, C. M., Fedo, C. M., et al. (b). Evidence for a diagenetic origin of Vera Rubin ridge, Gale crater, Mars: Summary and synthesis of Curiosity's exploration campaing. Journal of Geophysical Research: Planets, 2020JE006527R

Frydenvang, J., Mangold, N., Wiens, R. C., Fraeman, A. A., Edgar, L. A., Fedo, C., et al. (2019). The role of large-scale diagenesis in the formation of Vera Rubin ridge in Gale crater, Mars, as implied by ChemCam observations. 50th Lunar Planet. Sci. Conf., Abstract \#1863.

Frydenvang, J., Mangold, N., Wiens, R. C., Fraeman, A. A., Edgar, L. A., Fedo, C., et al. The chemostratigraphy of the Murray formation and role of diagenesis at Vera Rubin ridge in Gale crater, Mars, as observed by the ChemCam instrument. Journal of Geophysical Research: Planets, 2019JE006320RRRR

Gabriel, T. S. J., Hardgrove, C., Czarnecki, S., Rampe, E. B., Rapin, W., Achilles, C. N., et al., (2018). Water abundance of Dunes in Gale crater, Mars from Active Neutron Experiments and implications for amorphous phases. Geophysical Research Letters, 45(23), 12, 766-775, https://doi.org/10.1029/2018GL079045

Girty, G. H., Mossman, B. J., and Pincus, S. D. (1988). Petrology of Holocene sand, peninsular 
ranges, California and Baja Norte, Mexico; implications for provenance-discrimination models. Journal of Sedimentary Research, 58(5), 881-887.

Glotch, T. D., Morris, R. V., Christensen, P. R., \& Sharp, T. G. (2004). Effect of precursor mineralogy on the thermal infrared emission spectra of hematite: Application to Martian hematite mineralization. Journal of Geophysical research: Planets, 109(E7), https://doi.org/10.1029/2003je002224

Goetz, W., Bertelsen, P., Binau, C. S., Gunnlaugsson, H. P., Hviid, S. F., Kinch, K. K., et al. (2005). Indication of drier periods on Mars from the chemistry and mineralogy of atmospheric dust. Nature, 436, 62-65. https://doi.org/10.1038/nature03807

Gooding, J. L. (1978). Chemical weathering on Mars thermodynamic stabilities of primary minerals (and their alteration products) from mafic igneous rocks. Icarus, 33(3), 483-513. https://doi.org/10.1016/0019-1035(78)90186-0

Grotzinger, J. P., Vasavada, A. R., Anderson, R. C., Baker, C. J., Barry, R., Blake, D. F., et al. (2012). Mars Science Laboratory Mission and Science Investigation. Space Science Reviews, 170(1), 5-56. https://doi.org/10.1007/s11214-012-9892-2

Grotzinger, J. P., Sumner, D. Y., Kah, L. C., Stack, K., Gupta, S., Edgar, L., et al. (2014). A habitable fluvio-lacustrine environment at Yellowknife Bay, Gale crater, Mars. Science, 343(6169), 1242777. https://doi.org/10.1126/science.1242777

Grotzinger, J. P., Gupta, S., Malin, M. C., Rubin, D. M., Schieber, J., Siebach, K., et al. (2015). Deposition, exhumation, and paleoclimate of an ancient lake deposit, Gale crater, Mars. Science, 350(6257),. https://doi.org/10.1126/science.aac7575

Guo, H., \& Barnard, A. S. (2011). Thermodynamic modelling of nanomorphologies of hematite and goethite. Journal of Materials Chemistry A, 21, 11566-11577

Guo, H., \& Barnard, A. S. (2013). Naturally occurring iron oxide nanoparticles: morphology, surface chemistry and environmental stability. Journal of Materials Chemistry A, 1, 2742

Horgan, B., Johnson, J. R., Fraeman, A. A., III, J. F. B., Bennett, K., Cloutis, E., et al., Diagenesis of Vera Rubin ridge, Gale crater, Mars from Mastcam multispectral images. Journal of Geophysical Research: Planets, 2019JE006322

Hardgrove, C., Moersch, J., and Drake, D. (2011). Effects of geochemical composition on neutron die-away measurements: Implications for Mars Science Laboratory's Dynamic Albedo of Neutrons experiment. Nuclear Instruments and Methods in Physics Research Section A: Accelerators, Spectrometers, Detectors and Associated Equipment, 659(1), 442-455

Hurowitz, J. A., Fischer, W. W., Tosca, N. J., Milliken, R. E. (2010). Origin of acidic surface waters and the evolution of atmospheric chemistry on early Mars. Nature Geoscience, 3(5), 323-326.

Hurowitz, J. A., Grotzinger, J. P., Fischer, W. W., McLennan, S. M., Milliken, R. E., Stein, N., et al. (2017). Redox stratification of an ancient lake in Gale crater, Mars. Science, 356(6341). https://doi.org/10.1126/science.aah6849

Jacob, S. R., Wellington, D., III, J. F. B., Achilles, C., Fraeman, A. A., Horgan, B., et al., Spectral, Compositional, and Physical Properties of the Upper Murray Formation and Vera Rubin Ridge, Gale Crater, Mars. Journal of Geophysical Research: Planets, 2019JE006290RR

Johnsson, M. J. (1990). Tectonic versus chemical-weathering controls on the composition of fluvial sands in tropical environments. Sedimentology, 37(4), 713-726.

Johnsson, M. J., Stallard, R. F, and Lundberg, N. (1991). Controls on the composition of fluvial sands from a tropical weathering environment: sands of the Orinoco river drainage basin, Venezuela and Colombia. Geological Society of America, 103(12), 1622-1647.

Johnson, J. R., Bell, J. F., Bender, S., Blaney, D., Cloutis, E., DeFlores, L., et al. (2015). 
ChemCam passive reflectance spectroscopy of surface materials at the Curiosity landing site, Mars. Icarus, 249, 74-92. https://doi.org/10.1016/j.icarus.2014.02.028

Johnson, J. R., Bell, J. F., Bender, S., Blaney, D., Cloutis, E., Ehlmann, B., et al. (2016). Constraints on iron sulfate and iron oxide mineralogy from ChemCam visible/nearinfrared reflectance spectroscopy of Mt. Sharp basal units, Gale Crater, Mars. American Mineralogist, 101(7), 1501-1514. https://doi.org/10.2138/am-2016-5553

Knight, A. K., Scherbarth, N. L., Cremers, D. A., \& Ferris, M. J. (2000). Characterization of Laser-Induced Breakdown Spectroscopy (LIBS) for Application to Space Exploration. Applied Spectroscopy, 54(3), 331-340. https://doi.org/10.1366/0003702001949591

Lanza, N. L., Clegg, S. M., Wiens, R. C., McInroy, R. E., Newsom, H. E., \& Deans, M. D. (2012). Examining natural rock varnish and weathering rinds with laser-induced breakdown spectroscopy for application to ChemCam on Mars. Applied Optics, 51(7), B74-B82. https://doi.org/10.1364/AO.51.000B74

Lanza, N. L., Fischer, W. W., Wiens, R. C., Grotzinger, J. P., Ollila, A. M., Cousin, A., et al. (2014). High manganese concentrations in rocks at Gale crater, Mars. Geophysical Research Letters, 41(16), 5755-5763. https://doi.org/10.1002/2014GL060329

Lanza, N. L., Wiens, R. C., Arvidson, R. E., Clark, B. C., Fischer, W. W., Gellert, R., et al. (2016). Oxidatation of manganese in an ancient aquifer, Kimberley formation, Gale crater, Mars. Geophysical Research letter, 43, 7398-7407, doi:10.1002/2016GL069109.

Lasue, J., Wiens, R. C., Clegg, S. M., Vaniman, D. T., Joy, K. H., Humphries, S., et al. (2012). Remote laser-induced breakdown spectroscopy (LIBS) for lunar exploration. Journal of Geophysical Research: Planets, 117(E1). https://doi.org/10.1029/2011JE003898

Lasue, J., Clegg, S. M., Forni, O., Cousin, A., Wiens, R. C., Lanza, N., et al. (2016). Observation of $>5$ wt.\% zinc at the Kimberley outcrop, Gale crater, Mars. Journal of Geophysical Research: Planets, 121(3), 338-352. https://doi.org/10.1002/2015JE004946

Lasue, J., Cousin, A., Meslin, P. Y., Mangold, N., Wiens, R. C., Berger, G., et al. (2018). Martian eolian dust probed by ChemCam. Geophysical Research Letters, 45(20). https://doi.org/10.1029/2018GL079210

Le Mouélic, S., Gasnault, O., Herkenhoff, K. E., Bridges, N. T., Langevin, Y., Mangold, N., et al. (2015). The ChemCam Remote Micro-Imager at Gale crater: Review of the first year of operations on Mars. Icarus, 249, 93-107. https://doi.org/10.1016/j.icarus.2014.05.030

L'Haridon, J., Mangold, N., Fraeman A. A., Johnson, J. R., Cousin, A., Rapin, W., et al. Iron Mobility during Diagenesis as Observed by ChemCam at the Vera Rubin Ridge, Gale Crater, Mars. Journal of Geophysical Research: Planets, 2019JE006299R

Litvak, M. L., Mitrofanov, I. G., Barmakov, Y. N., Behar, A., Bitulev, A., Bobovnitsky, Y., et al. (2008). The Dynamic Albedo of Neutrons (DAN) Experiment for NASA's 2009 Mars Science Laboratory. Astrobiology, 8(3), 93. https://doi.org/10.1089/ast.2007.0157

Mahaffy, P. R., Webster, R., Cabane, M., Conrad, P. G., Coll, P., Atreya, S. K., et al. (2012). The sample analysis at Mars investigation and instrument suite. Space Science review, 170(1-4), 401-478.

Malin, M. C., Ravine, M. A., Caplinger, M. A., Ghaemi, F. T., Schaffner, J. A., Justin, N., et al. (2017). The Mars Science Laboratory (MSL) Mast cameras and Descent imager: Investigation and instrument descriptions. Earth and Space Science, 4(8), 506-539.

Mangold, N., Dehouck, E., Fedo, C., Forni, O., Achilles, C., Bristow, T., et al. (2019). Chemical alteration of fine-grained sedimentary rocks at Gale crater. Icarus, 321, 619-631. https://doi.org/10.1016/j.icarus.2018.11.004 
Maurice, S., Wiens, R. C., Saccoccio, M., Barraclough, B., Gasnault, O., Forni, O., et al. (2012). The ChemCam Instrument Suite on the Mars Science Laboratory (MSL) Rover : Science Objectives and Mast Unit Description. Space Science Reviews, 170(1), 95-166. https://doi.org/10.1007/s11214-012-9912-2

Maurice, S., Clegg, S. M., Wiens, R. C., Gasnault, O., Rapin, W., Forni. O., et al. (2016). ChemCam activities and discoveries during the nominal mission of Mars Science Laboratory in Gale crater, Mars, Journal of Analytical Atomic Spectroscopy, 31:863889, doi:10.1039/C5JA00417A, 2016.

Marshall, C. P., \& Fairbridge, R. W. (1998). Encyclopedia of Geochemistry, Springer.

McAdam, A. C., Sutter, B., Archer, P. D., Franz, H. B., Wong, G. M., Lewis, J. M. T., et al., Constraints on the Mineralogy and Geochemistry of the Vera Rubin ridge, Gale crater, Mars, from Mars Science Laboratory Sample Analysis at Mars Evolved Gas. Journal of Geophysical Research: Planets, 2019JE006309R

McLennan, S. M., Bell, J. F., Calvin, W. M., Christensen, P. R., Clark, B. C., De Souza, P. A., et al. (2005). Provenance and diagenesis of the evaporite-bearing Burns formation, Meridiani Planum, Mars. Earth and Planetary Science Letters, 240(1), 95-121. https://doi.org/10.1016/j.epsl.2005.09.041

Meslin, P. Y., Johnson, J. R., Forni, O., Beck, P., Cousin, A., Bridges, J., et al. (2017). Egg Rock encounter: analysis of an iron-nickel meteorite found in Gale crater by Curiosity. 48th Lunar Planet. Sci. Conf., Abstract \#2258.

Meslin, P. Y., Gasda, P. J., L’Haridon, J., Forni, O., Lanza, N. L., Lamm, S., et al. (2018). Detection of Hydrous Manganese and Iron Oxides with Variable Phosphorus and Magnesium Contents in the Lacustrine Sediments of the Murray Formation, Gale, Mars. 49th Lunar Planet. Sci. Conf., Abstract \#1447.

Meslin, P. Y., Wellington, D., Wiens, R. C., Johnson, R. C., Van Beek, J., Gasnault, O., et al. (2019). Diversity and areal density of iron-nickel meteorites analyzed by ChemCam in Gale. 50th Lunar Planet. Sci. Conf., Abstract \#3179.

Milliken, R. E., Grotzinger, J. P., \& Thomson, B. J. (2010). Paleoclimate of Mars as captured by the stratigraphic record in Gale Crater. Geophysical Research Letters, 37(4). https://doi.org/10.1029/2009GL041870

Mitra, K., \& Catalano, J. G. (2019). Chlorates as a potential oxidant on Mars: Rates and products of dissolved Fe(II) oxidation. Journal of Geophysical Research: Planet. https://doi.org/10.1029/2019JE006133

Morris, R. V., Agresti, D. G., Lauer, H. V., Newcomb, J. A., Shelfer, T. D., \& Murali, A. V. (1989). Evidence for pigmentary hematite on Mars based on optical, magnetic, and Moessbauer studies of superparamagnetic (nanocrystalline) hematite. Journal of Geophysical Research, 94, 2760-2778. https://doi.org/10.1029/JB094iB03p02760

Morris, R. C., Golden, D. C., \& Lauer, H. V. (1998). Lepidocrocite to maghemite to hematite : A pathway to magnetic and hematitic Martian soil. Meteoritics \& Planetary Science, 33(4), 743-751.

Morris, R. V., Klingelöfer, G., Schröder, C., Rodionov, D. S., Yen, A., Ming, D. W., et al. (2006). Mössbauer mineralogy of rock, soil, and dust at Gusev crater, Mars : Spirit's journey through weakly altered olivine basalt on the plains and pervasively altered basalt in the Columbia Hills. Journal of Geophysical Research : Planets, 111(E2)

Morrison, S. M., Downs, R. T., Blake, D. F., Vaniman, D. T., Ming, D. W., Hazen, R. M., et al. (2018). Crystal chemistry of martian minerals from Bradbury Landing through Naukluft Plateau, Gale crater, Mars. American Mineralogist, 103(6), 857-871. https://doi.org/10.2138/am-2018-6124

Mücke, A. (1994). Postdiagenetic ferruginization of sedimentary rocks (sandstones, oolitic ironstones, kaolins, and bauxites). Including a comparative study of the reddening of 
red beds. Developments in Sedimentology, 51, 361-395. https://doi.org/10.1016/S00704571(08)70444-8

Murchie, S. L., Arvidson, R. E., Bedini, P., Beisser, K., Bibring, J. P., Bishop, J., et al. (2007). Compact Reconnaissance Imaging Spectrometer for Mars (CRISM) on Mars Reconnaissance Orbiter (MRO). Journal of Geophysical Research : Planets, 112(E5),

Ollila, A. M., Horton, H. E., Benton, C., Wiens, R. C., Cousin, A., Blank, J. G., et al. (2014). Trace element geochemistry ( $\mathrm{Li}, \mathrm{Ba}, \mathrm{Sr}$ and $\mathrm{Rb}$ ) using Curiosity's ChemCam: Early results for Gale crater from Bradbury landing site to Rocknest. Journal of Geophysical Research: Planets, 119(1). https://doi.org/10.1002/2013JE004517

Ormö, J., Komatsu, G., Chan, M. A., Beitler, B., \& Parry, W. T. (2004). Geological features indicative of processes related to the hematite formation in Meridiani Planum and Aram Chaos, Mars: a comparison with diagenetic hematite deposits in the southern Utah, USA. Icarus, 171, 295-316.

Palucis, M. C., Dietrich, W. E., Hayes, A. G., Williams, R. M. E., Gupta, S., Mangold, N., et al. (2014). The origin and evolution of the Peace Vallis fan system that drains to the Curiosity landing area, Gale Crater, Mars. Journal of Geophysical Research: Planets, 119(4), 705-728. https://doi.org/10.1002/2013JE004583

Payré, V., Fabre, C., Cousin, A., Sautter, V., Wiens, R. C., Forni, O., et al. (2017). Alkali trace elements in Gale crater, Mars, with ChemCam: Calibration update and geological implications. Journal of Geophysical Research : Planets, 122(3), 650-679.

Payré, V., Fabre, C., Sautter, V., Cousin, A., Mangold, N., Le Deit, L., et al. (2019). Copper enrichments in the Kimberley formation in Gale crater, Mars: Evidence for a $\mathrm{Cu}$ deposit at the source. Icarus, 321(15), 736-751. https://doi.org/10.1016/j.icarus.2018.12.015

Penn, R. L., \& Banfield, J. F. (1998) Imperfect Oriented Attachment: Dislocation Generation in Defect-Free Nanocrystals. Science, 281, 969-971. DOI: 10.1126/science.281.5379.969

Peters, G. H., Abbey, W., Bearman, G. H., Mungas, G. S., Smith, A., Anderson, R. C., et al., (2008) Mojave Mars simulant - Characterization of a new geologic Mars analog. ICarus, 197, 470-479.

Rampe, E. B., Ming, D. W., Blake, D. F., Bristow, T. F., Chipera, S. J., Grotzinger, J. P., et al. (2017). Mineralogy of an ancient lacustrine mudstone succession from the Murray formation, Gale crater, Mars. Earth and Planetary Science Letters, 471, 172-185. https://doi.org/10.1016/j.epsl.2017.04.021

Rampe, E. B., Bristow, T. F., Morrison, S. M., Achilles, C. N., Ming, D. W., Vaniman, D. T., et al. Mineralogy of Vera Rubin Ridge from the Mars Science Laboratory CheMin Instrument. Journal of Geophysical Research: Planets, 2019JE006306R

Rapin, W., Meslin, P. Y., Maurice, S., Vaniman, D., Nachon, M., Mangold, N., et al. (2016). Hydration state of calcium sulfates in Gale crater, Mars : Identification of bassanite veins. Earth and Planetary Science Letters, 452, 197-205. https://doi.org/10.1016/j.eps1.2016.07.045

Salvatore, M., Truitt, K., Roszell, K., Lanza, N, L., Rampe, E. B., Mangold, N., et al., (2019). Investigating the role of anhydrous oxidative weathering on sedimentray rocks in the Transantarctic Moutains and implications for the modern weathering of sedimentary lithologies on Mars. Icarus, 319, 669-684.

Schellmann, W. (1994). Geochemical differentiation in laterite and bauxite formation. Catena, 21(2), 131-143. https://doi.org/10.1016/0341-8162(94)90007-8

Sherman, D. M., \& Waite, T. D. (1985). Electronic spectra of Fe3+ oxides and oxide hydroxides in the near IR to near UV. American Mineralogist, 70(11-12), 1262-1269.

Stack, K. M., Grotzinger, J. P., Lam, M. P., Gupta, S., Rubin, D. M., Kah, L. C., et al. (2019). Evidence for plunging river plume deposits in the Pahrumps Hills member of the 
Murray formation, Gale crater, Mars. Sedimentology, 66(5), 1768-1802. https://doi.org/10.1111/sed.12558

Stein, N. T., Quinn, D. P., Grotzinger, J. P., Fedo, C. M., Ehlmann, B. L., Stack, K. M., et al. Regional structural orientation of the Mt. Sharp group revealed by in-situ dip measurements and stratigraphic correlations on the Vera Rubin ridge. Journal of Geophysical Research: Planets, 2019JE006298R

Sullivan, P. J., Yelton, J. L., \& Reddy, K. J. (1988). Iron sulfide oxidation and the chemistry of acid generation. Environmental Geology and Water Sciences, 11(3), 289-295.

Sun, V. Z., Stack, K. M., Kah, L. C., Thompson, L., Fischer, W., Williams, A. J., et al. (2019). Late-stage diagenetic concretions in the Murray formation, Gale crater, Mars. Icarus, 321, 866-890. https://doi.org/10.1016/j.icarus.2018.12.030

Suttner, L. J., Basu, A., and Mack, G. H. (1981). Climate and the origin of quartz arenites. Journal of geophysical research, 51(4), 1235-1246.

Thomson, B. J., Bridges, B. T., Milliken, R., Baldridge, A., Hook, S.J., Crowler, J. K., et al. (2011). Constraints on the origin and evolution of the layered mound in Gale crater, Mars, using Mars Reconnaissance Orbiter data. Icarus, 214, 413-432. doi:10.1016/j.icarus.2011.05.002.

Thompson, L. M. Fraeman, A. A., Berger, J. A., Rampe, E. B., Boyd, N. I., Gellert, R., et al. (2019). Compositional Characteristics and Trends Within the Vera Rubin Ridge, Gale Crater, Mars as Determined by APXS : Sedimentary, Diagenetic and Alteration History. 50th Lunar Planet. Sci. Conf., Abstract \#3269.

Thompson, L. M., Fraeman, A. A., Berger, J. A., Boyd, N. I., Gellert, R., O’Connell-Cooper, C., et al. APXS-derived compositional characteristics of the Vera Rubin Ridge, Gale crater, Mars: Geochemical implications for the origin of the ridge. Journal of Geophysical Research: Planets, 2019JE006319R

Vigliotti, L., Capotondi, L., \& Masayeda, T. (1999). Magnetic properties of sediments deposited in suboxic-anoxic environments: Relationships with biological and geochemical proxies. Geological Society London Special Publications, 151, 71-83. https://doi.org/10.1144/GSL.SP.1999.151.01.08

Wiens, R. C., Maurice, S., Lasue, J., Forni, O., Anderson, R. B., Clegg, S., et al. (2013). Preflight calibration and initial data processing for the ChemCam laser-induced breakdown spectroscopy instrument on the Mars Science Laboratory rover. Spectrochimica Acta Part B: Atomic Spectroscopy, 82, 1-27. https://doi.org/10.1016/j.sab.2013.02.003

Wiens, R. C., Maurice, S., Barraclough, B., Saccoccio, M., Barkley, W. C., Bell, J. F., et al. (2012). The ChemCam Instrument Suite on the Mars Science Laboratory (MSL) Rover: Body Unit and Combined System Tests. Space Science Reviews, 170(1), 167-227. https://doi.org/10.1007/s11214-012-9902-4

Williams, R. M. E., Grotzinger, J. P., Dietrich, W. E., Gupta, S., Sumner, D. Y., Wiens, R. C., et al. (2013). Martian Fluvial Conglomerates at Gale Crater. Science, 340(6136), 1068-1072. https://doi.org/10.1126/science. 1237317

Wilson, S. A. (1997). Data compilation for USGS reference material BHVO-2, Hawaiian Basalt, U.S. Geological Survey, Open-File Report.

Wong, G. M., Lewis, J. M. T., Knudson, C. A., Millan, M., S, A., Navarro-Gonzalez, R., et al., Detection of reduced sulfur on Vera Rubin ridge by quadratic discriminant analysis of volatiles observed during evolved gas analysis. Journal of Geophysical Research: Planets, 2019JE006304R

Zolotov, M. Y., \& Shock, E. L. (2005). Formation of jarosite-bearing deposits through aqueous oxidation of pyrite at Meridiani Planum, Mars. Geophysical Research Letters, 32(21). https://doi.org/10.1029/2005GL024253 

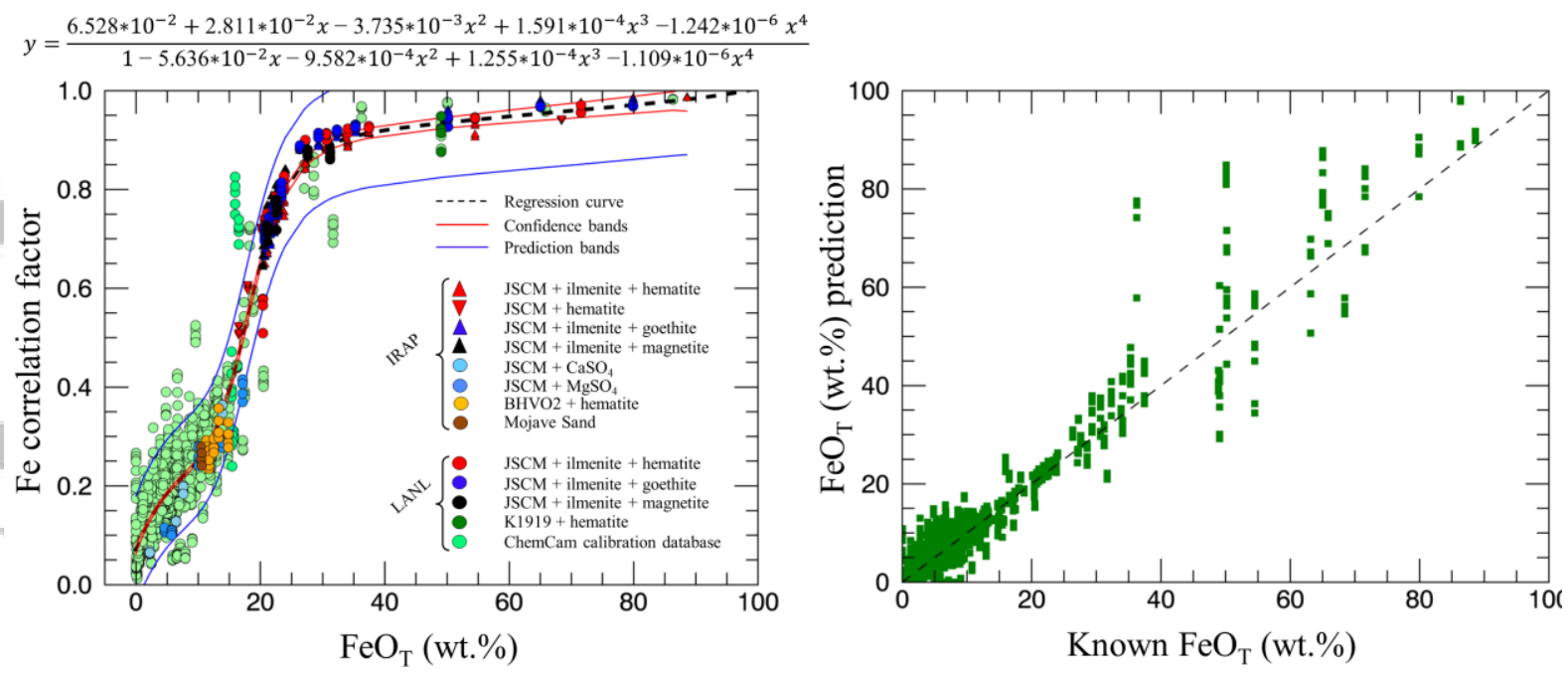

Figure 1: a) Regression curve showing the Fe correlation factor (or Pearson correlation factor) as a function of the $\mathrm{FeO}_{\mathrm{T}}$ (wt.\%) in the reference samples. Spectra acquired with both IRAP and LANL laboratory setups are represented. Spectra obtained on K1919 basaltic products mixed with hematite (1:1 ratio) were also used and were sampled with the LANL laboratory instrument [Anderson et al., 2017a]. All points are fitted with a fourth-degree polynomial function (dashed line), and the corresponding equation is represented. Red lines correspond to the $95 \%$ confidence bands and blue lines to the $95 \%$ prediction bands. The limit of detection (LOD) and the critical level $\left(\mathrm{L}_{\mathrm{c}}\right)$ of hematite above average $\mathrm{FeO}_{\mathrm{T}}$ encountered in Gale bedrock $\left(\sim 19.5 \mathrm{FeO}_{\mathrm{T}}\right.$ wt.\%) are graphically obtained based on the prediction bands (see text). b) $\mathrm{FeO}_{\mathrm{T}}$ (wt.\%) predicted by the model for each ChemCam observation points of the geological samples as a function of the known $\mathrm{FeO}_{\mathrm{T}}($ wt.\%) compositions. The dashed line corresponds to the 1:1 ratio. 

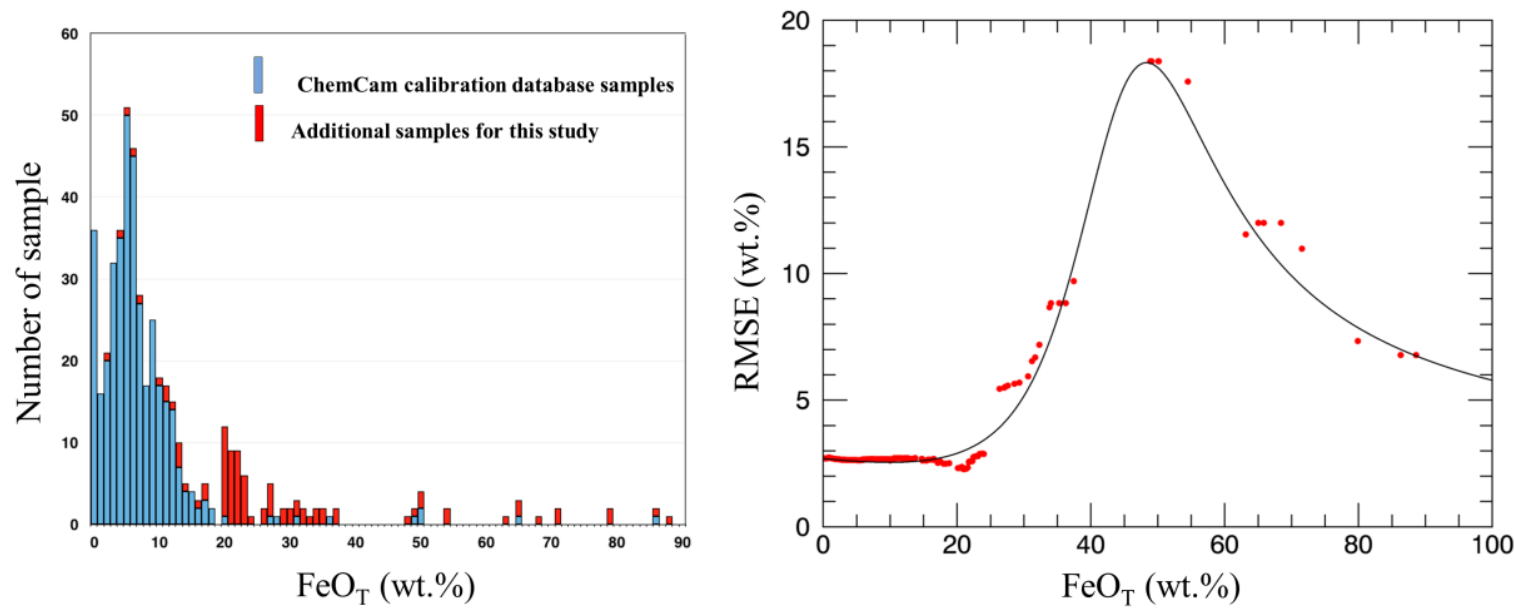

Figure 2: a) The number of samples as the function of their iron composition used to build the model. b) Root-means-square error of prediction (RMSE) calculated from Eq. 1 as a function of the wt.\% FeOT. of the samples used to build the model. The RMSE is computed for all samples within a window of $\pm 10 \mathrm{wt} . \% \mathrm{FeO}_{\mathrm{T}}$. 


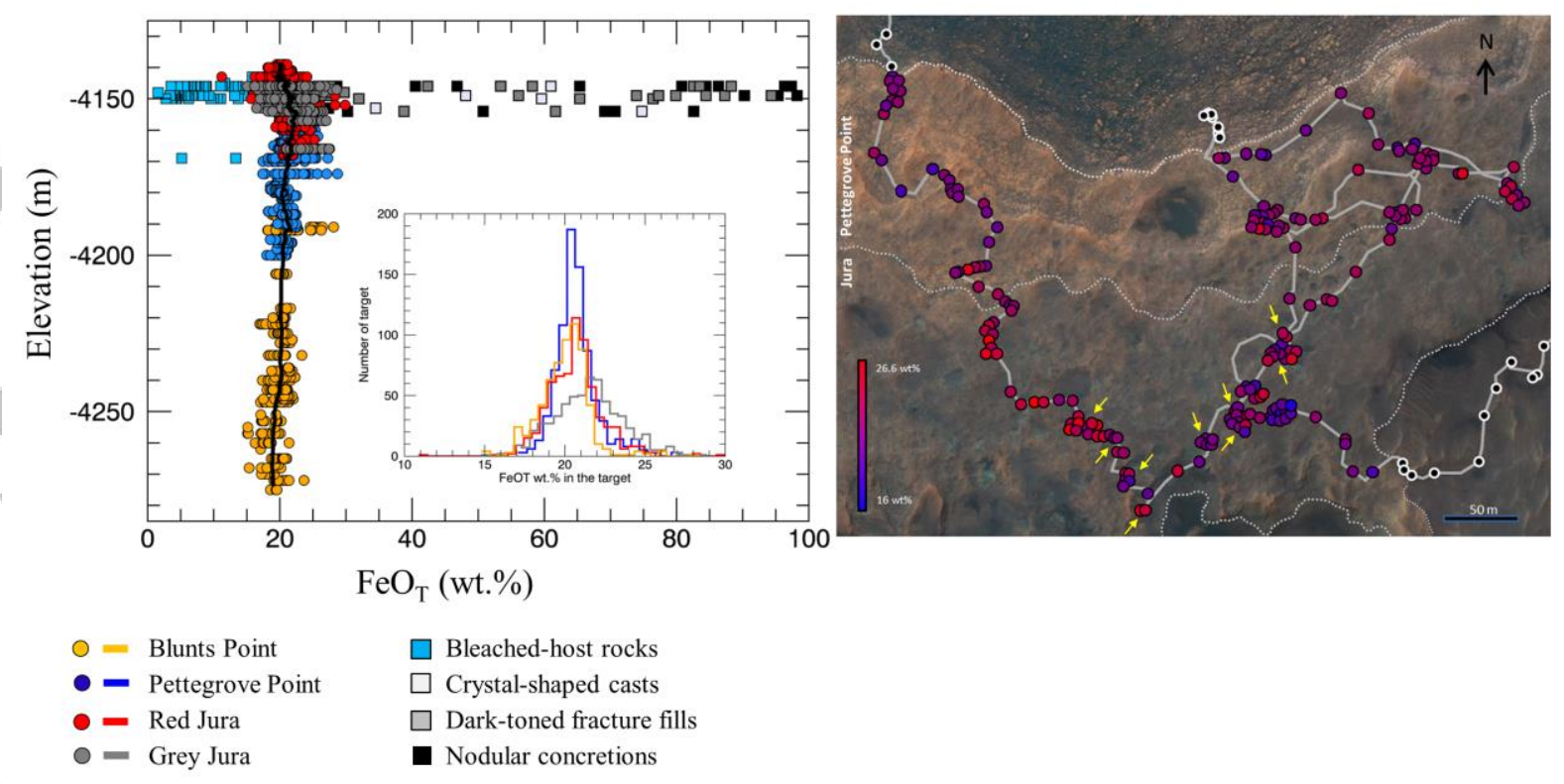

Figure 3: a) Iron abundance in martian bedrock as a function of the elevation (from sol 1697 to 2300 of the mission). Targets from Murray formation are represented: Blunts Point member (orange circles), Pettegrove Point member (blue circles), red Jura member (red circles) and grey Jura member (grey circles). Running average smoothed with a width of 150 points. Diagenetic features such as bleached host rocks (blue squares), crystal-shaped casts (white squares), dark-toned fracture fills (gray squares) and nodular concretions (black squares) are also represented. In addition, the histogram showing the iron distribution in Blunts Point member (orange line), Pettegrove Point member (blue line), red Jura member (red line) and grey Jura member (grey line), for ChemCam observation points is presented (without diagenetic features). b) Average iron abundance per target plotted on the HiRISE mosaic at VRR (excluding diagenetic features such as dark-toned features or calcium sulfate veins). Color code indicates the iron abundances from low (blue) to high (red) areas. The yellow arrows correspond to areas where dark-toned features were encountered. 


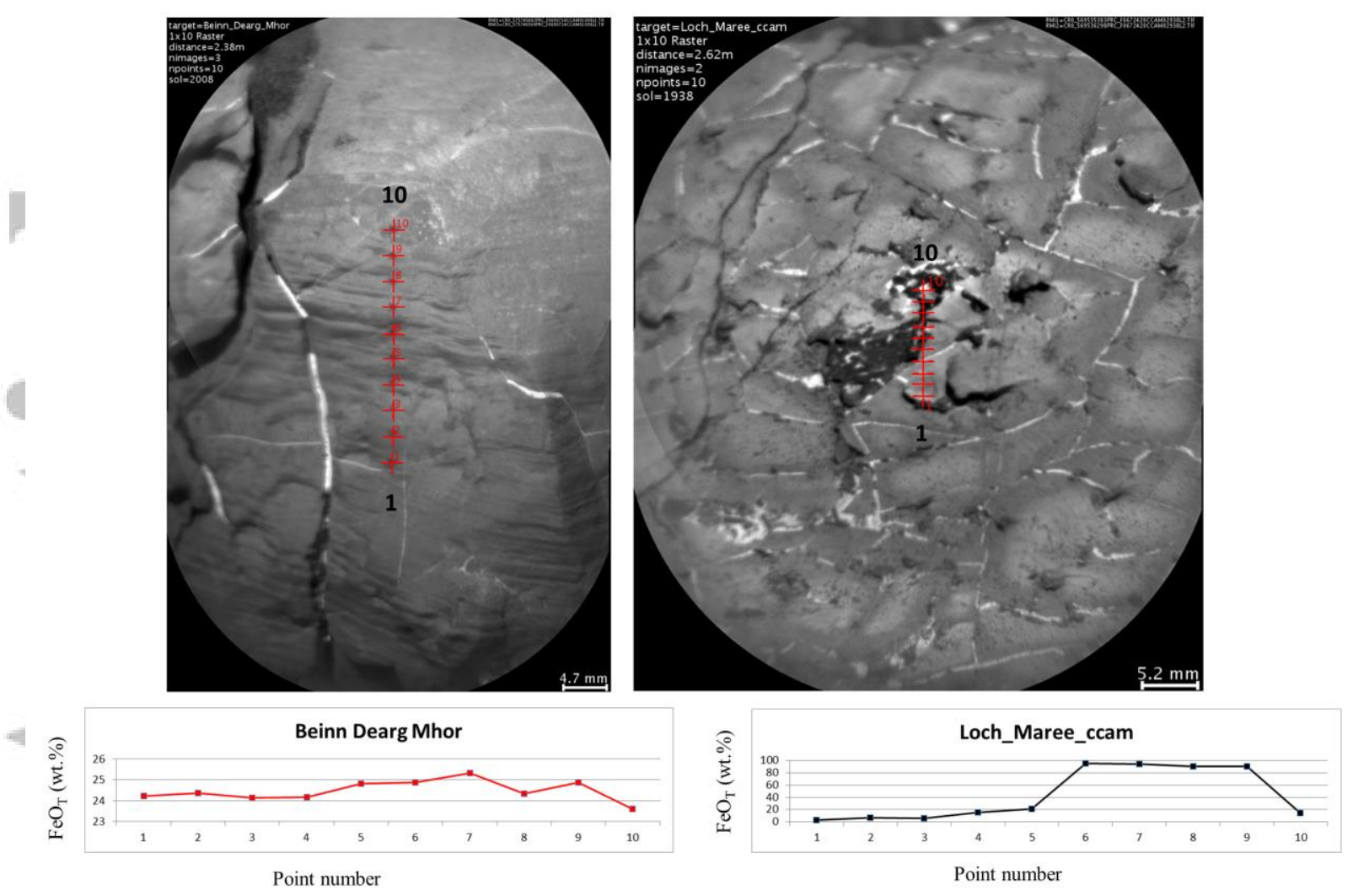

Figure 4: RMI context image of the a) Loch_Maree_ccam (sol 1938) and b) Beinn_Dearg_Mhor (sol 2008) targets. Iron abundance is also shown for each ChemCam observation point of the sequence. In the Loch_Maree target, dark-toned features were hit in points \#6, 7, 8 and 9; and bleached-halos in points (\#1,\#2 and \#3). Note the different scale of the $y$-axis between the two plots. 


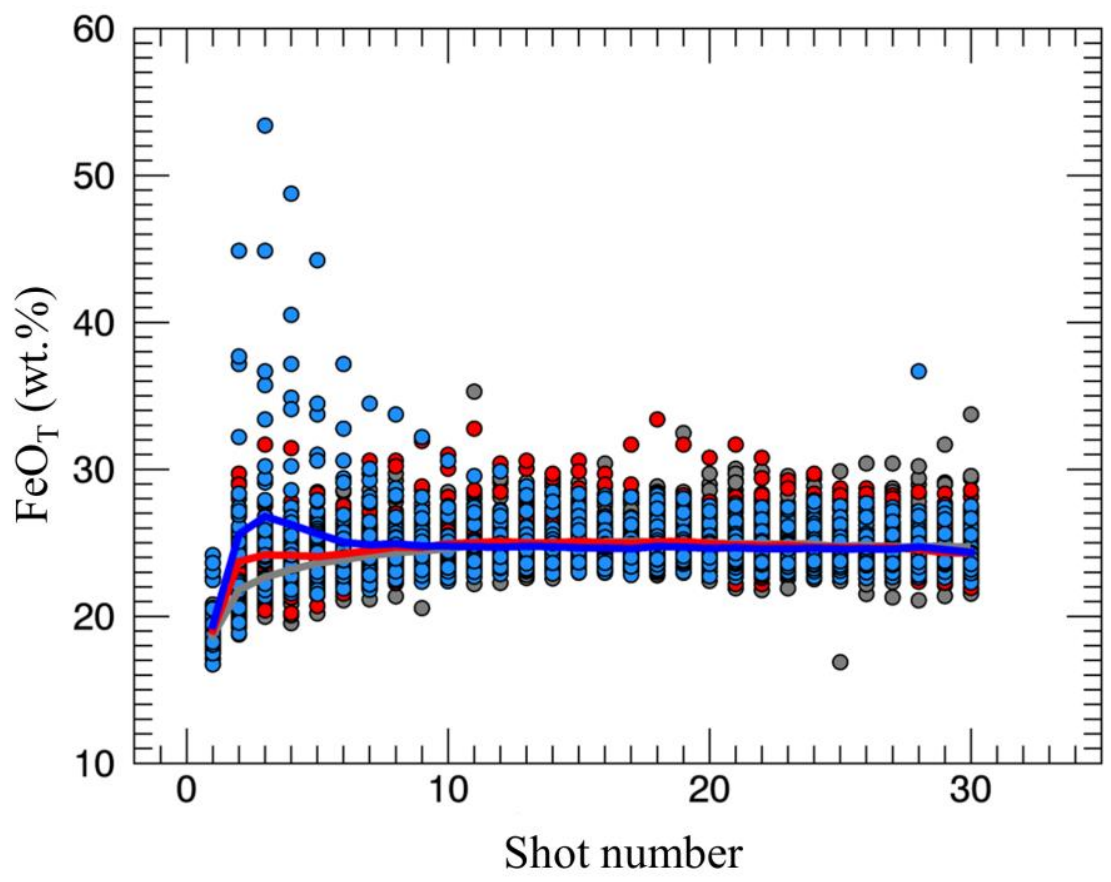

Figure 5: Shot-to-shot depth profiles for all ChemCam observations points of the high-iron group (>23.5 wt. \% $\mathrm{FeO}_{\mathrm{T}}$ ), for the three members of VRR. Pettegrove Point, the red and grey Jura members are respectively represented in blue, red and grey. The average per shot number is represented to highlight the overall lack of variation with depth. The first shots are often considered as probing a mixture of the bedrock and the dust cover and usually show low iron abundances, but they are not used to estimate bulk compositions. In the Pettegrove Point member (blue dots), some shots show higher iron abundances (up to $54 \mathrm{wt} . \% \mathrm{FeO}_{\mathrm{T}}$ ), which are probably associated with the presence of coarse-grained Fe-rich phases, or with high-iron dust, or with a thin high-iron layer. 


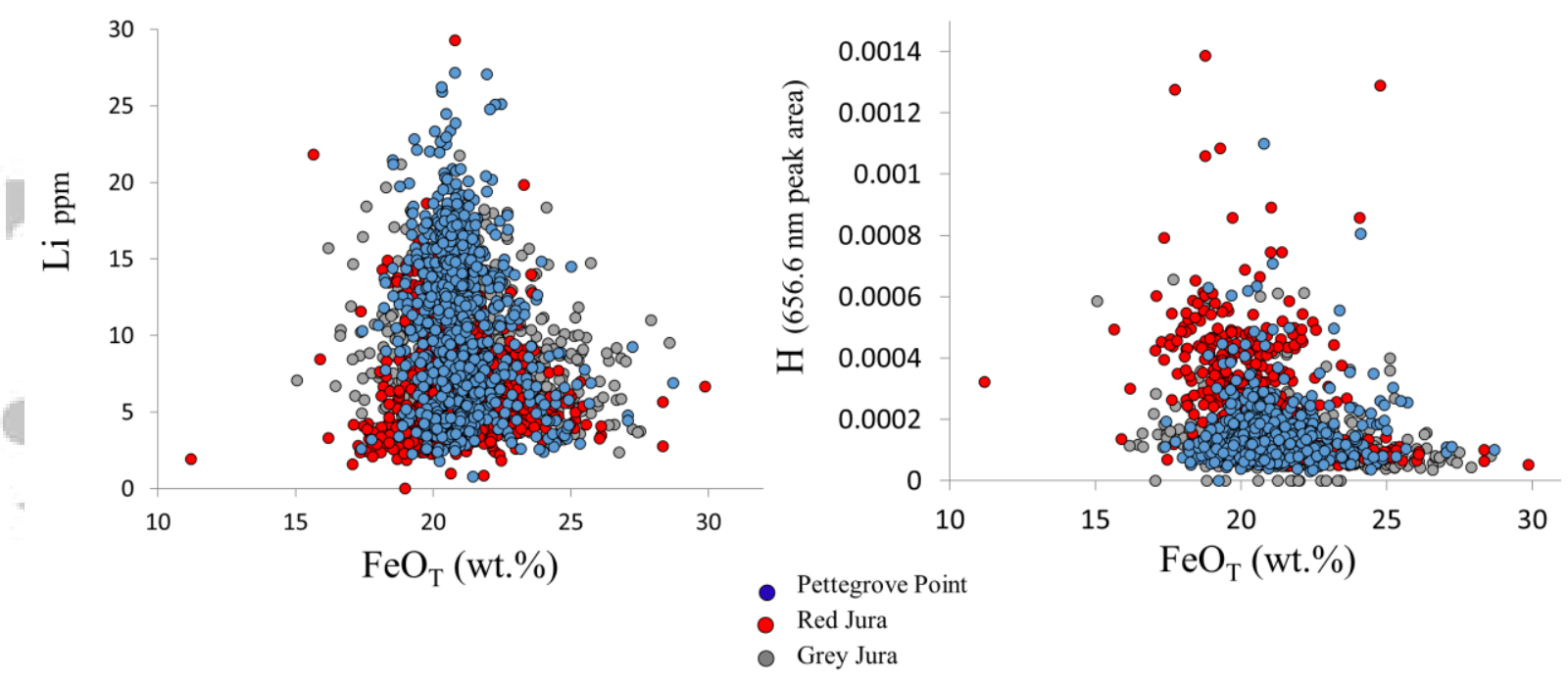

Figure 6: $\mathrm{FeO}_{\mathrm{T}}$ abundances (wt. \%) for individual ChemCam observation points in VRR bedrock as a function of $\mathrm{H}$ (the $656.6 \mathrm{~nm}$ emission line area) and $\mathrm{Li}$ (in ppm from the $670 \mathrm{~nm}$ emission line) for Pettegrove Point, the red and grey Jura members. All diagenetic features (dark-toned features, bleached-halos, light-toned veins) were removed from the dataset. 


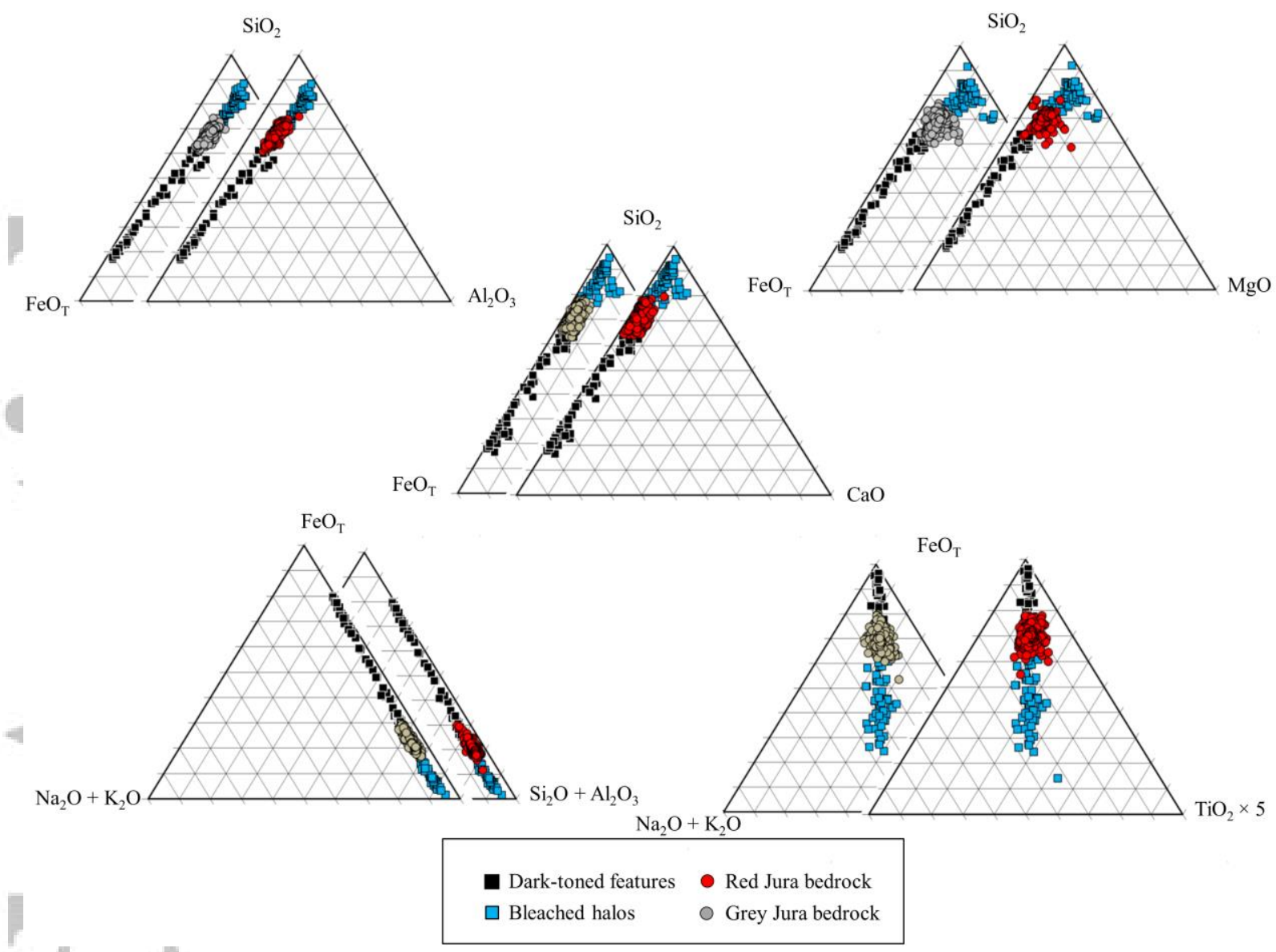

Figure 7: Ternary plots showing major elements quantified by ChemCam (in molar proportions) for red Jura (red dots, right plots of each pair) and grey Jura (grey dots, left plots of each pair) bedrock (diagenetic features were removed). Dark-toned features (black squares) and associated bleached halos (blue squares) are also represented. Similarly to bedrock data, only dark-toned features and bleached host rocks showing less than $5 \mathrm{wt} . \% \mathrm{CaO}$ are represented in the ternary plots. Iron variability observed directly within red and grey Jura bedrock plots along a mixing line, similarly to dark-toned features and bleached-halos. 


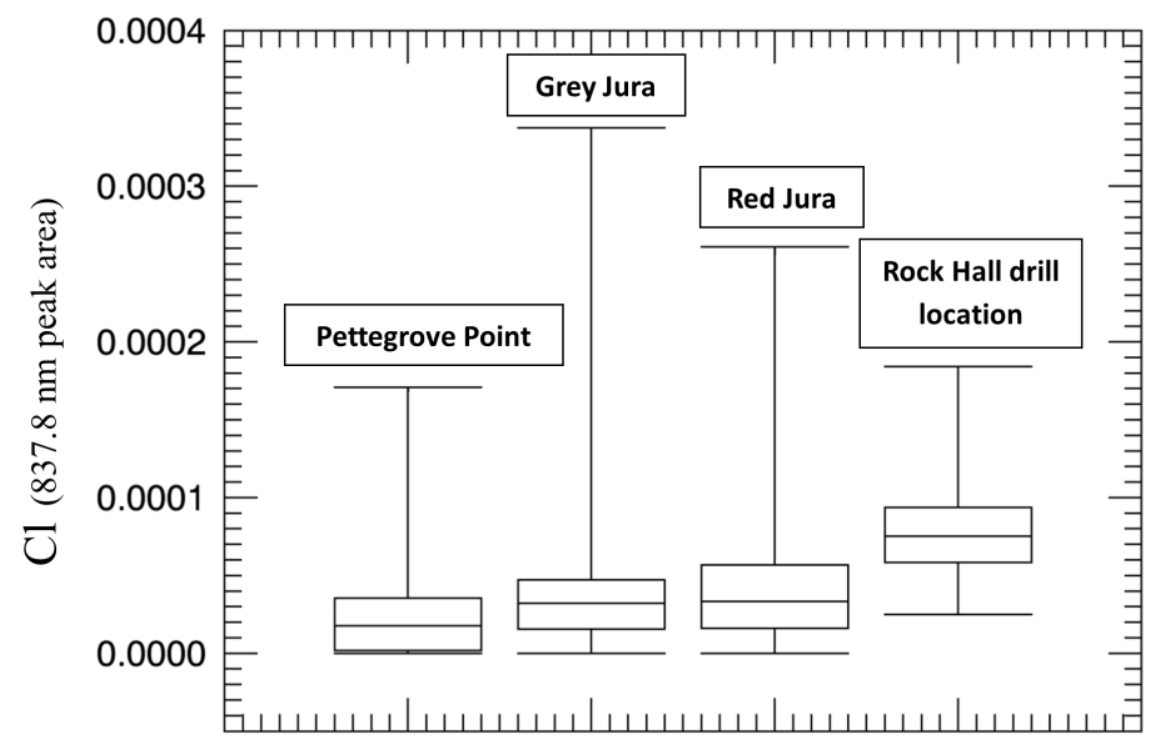

Figure 8: Box plots showing the minimum (lower part of the whiskers), lower quartile (lower part of the box), median, upper quartile (upper part of the box), and maximum (upper part of the whiskers) values of the $837.8 \mathrm{~nm}$ chlorine peak area in Pettegrove Point, grey Jura, red Jura (excluding ChemCam data from the Rock Hall drill location), and ChemCam data from the Rock Hall drill location. In order to avoid any contribution with possible halite detections Narich points have been removed $\left(\mathrm{Na}_{2} \mathrm{O}>3.5\right.$ wt. \%). 

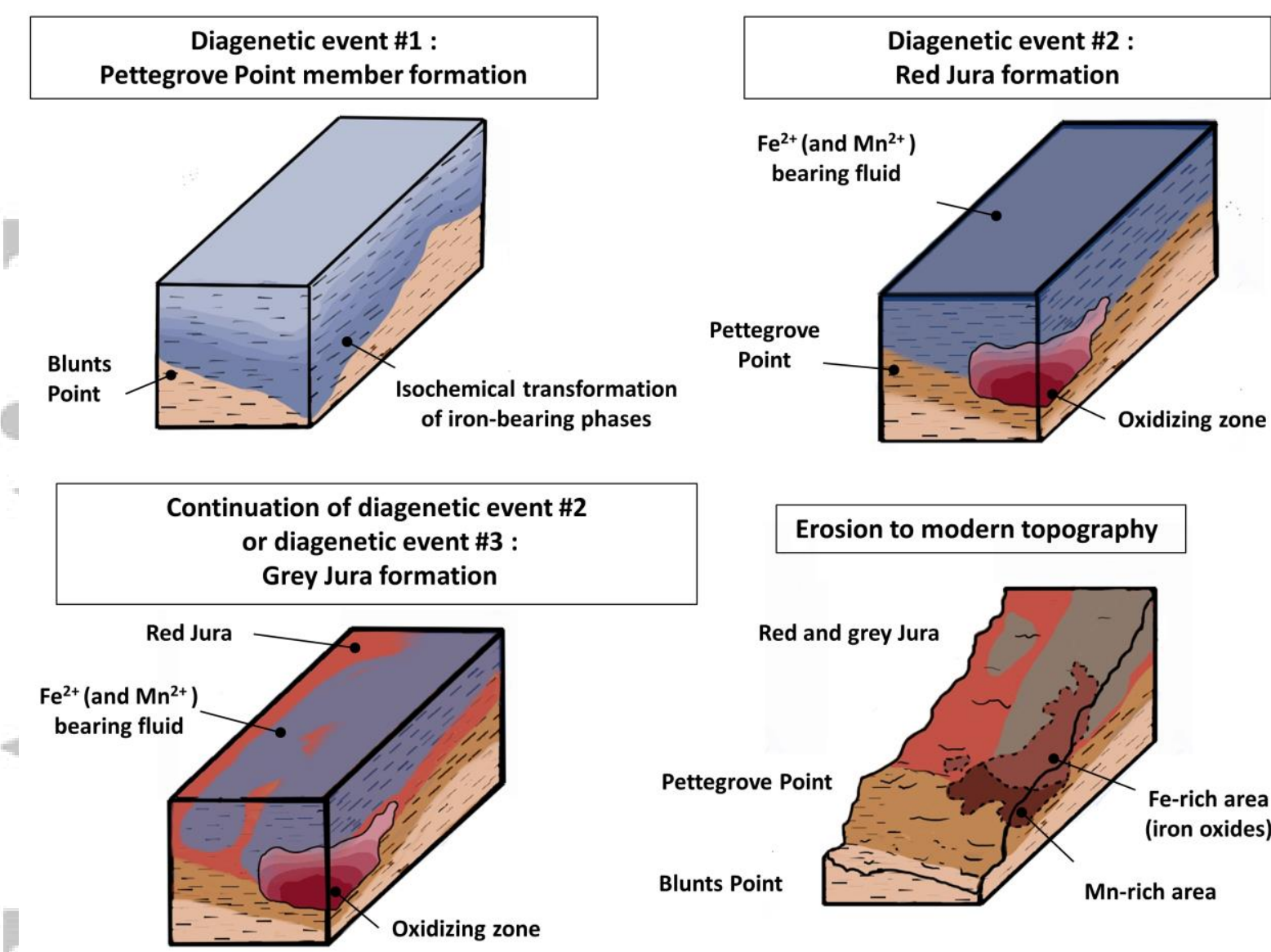

Figure 9: Summary of the proposed sequence of events. a. After sediments were deposited in a lacustrine environment, with a bulk chemical composition similar to the Blunts Point member, a first diagenetic event formed the Pettegrove Point member. The high hematite abundance can be the result of chemical weathering of precursors such as Fe-phyllosilicates or Fe-bearing amorphous components. b. A second diagenetic event involving slightly reducing fluids led to the formation of the red Jura. Fe and Mn are mobilized and are reprecipitated in localized oxidizing zones near the top of the Pettegrove Point member. This led to the overall decrease in $\mathrm{Mn}$ abundance in the red Jura rocks and the variability in Fe. c. The diagenetic event continued preferentially in some rocks, or a third diagenetic event occurred responsible for the grey Jura formation. Reducing fluids continued to mobilize Fe and $\mathrm{Mn}$ and accumulated in oxidizing zones. This would explain the higher variability in Fe abundances observed in these rocks and the overall lower Mn abundances. Fe precipitates before Mn under oxidizing conditions, leading to slightly shifted zones of accumulation. With time, coarsening processes occurred in the fluids (e.g., Ostwald ripening) leading to the formation of coarse-grained grey hematite. $d$. Sedimentary rocks are eroded. VRR appears as a ridge due to its diagenetic history that increases its resistance to erosion. 
Table 1: Average $\mathrm{FeO}_{\mathrm{T}}$ abundance observed in VRR bedrock (Pettegrove Point, red Jura, and grey Jura), and underlying member (Blunts Point). Standard deviations are reported in parentheses.

\begin{tabular}{llc} 
& Member & Average $\mathrm{FeO}_{\mathrm{T}}$ abundance (wt.\%) \\
\cline { 2 - 3 } & Blunts Point & $20.2(1.5)$ \\
Pettegrove Point & $21.0(1.3)$ \\
Red Jura & $20.9(1.7)$ \\
Grey Jura & $21.7(2.2)$ \\
All VRR & $21.2(1.8)$ \\
\hline
\end{tabular}

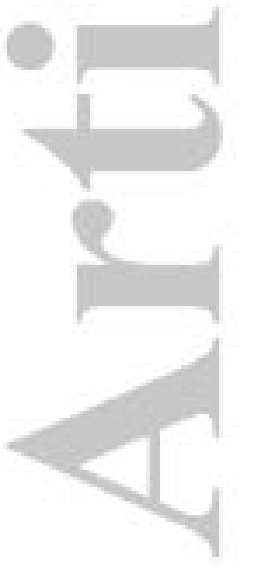

Grey Jura 21.2(1.8) 
Table 2: Mineralogy of the Fe-bearing phases observed in VRR by CheMin, and summary of some ChemCam observations. Fe-bearing phases are highlighted. 1-sigma errors are reported in parentheses for CheMin mineral abundances. Low major elements, $\mathrm{Li}$ and $\mathrm{H}$ abundances were associated with high-Fe points in all members. Also, no Fe-rich rock coatings were observed in any of the members.

\begin{tabular}{|c|c|c|}
\hline Member & Bulk mineralogy & ChemCam observations (chemistry) \\
\hline $\begin{array}{l}\text { Pettegrove Point } \\
\text { bedrock }\end{array}$ & 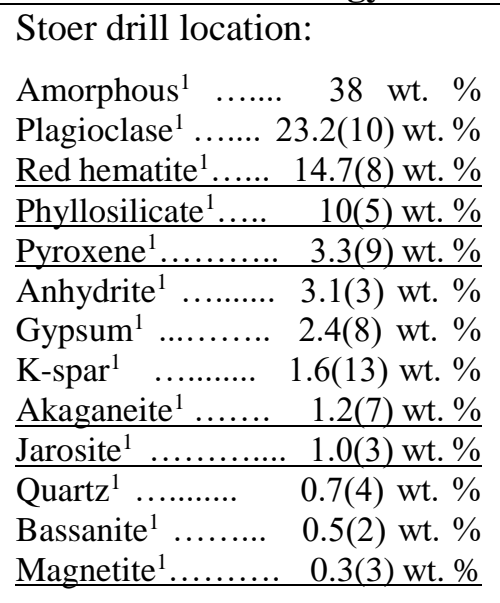 & $\begin{array}{l}\text { - High iron variability in the upper part of the } \\
\text { member }^{3} \\
\text { - High Mn abundances in the upper section }\end{array}$ \\
\hline
\end{tabular}

\section{Red Jura bedrock}

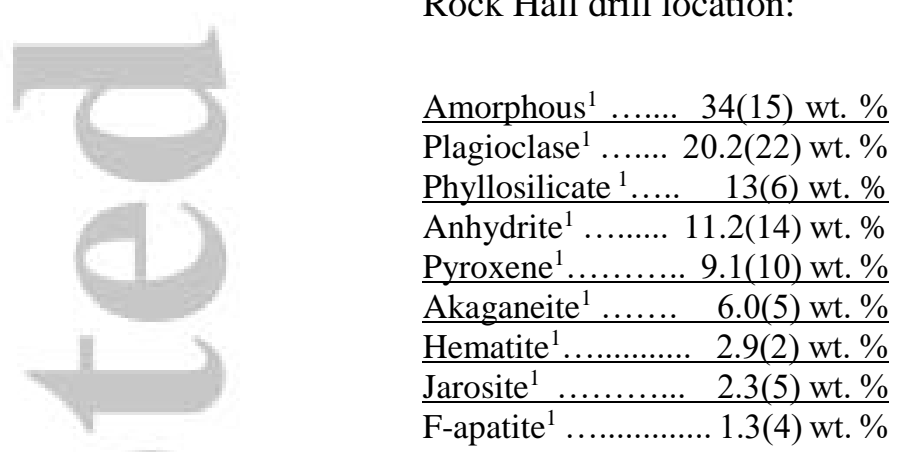

- Higher $\mathrm{Cl}$ in the Rock Hall drill location compared to the whole member. Slightly higher $\mathrm{Cl}$ in the red Jura compared to other VRR members (Fig. 8) ${ }^{3}$

- High iron variability in the member ${ }^{3}$

- Overall low Mn abundances ${ }^{4}$

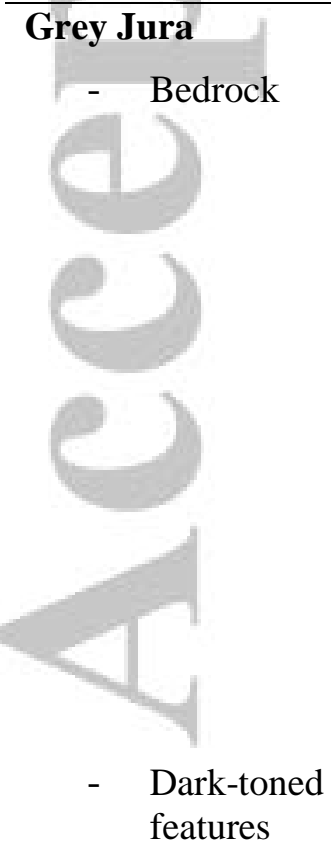

\section{Grey Jura}

Highfield drill location:

Amorphous $^{1}$

Plagioclase $^{1}$ .. 49 wt. $\%$ \begin{tabular}{lr} 
Grey hematite $^{1} \ldots$ & $8.5(5)$ wt. $\%$ \\
\hline Phyllosilicate $^{1}$ & $5(2)$ wt. $\%$
\end{tabular} Pyroxene ${ }^{1}$......... 4.2(15) wt. \% Opal-CT ${ }^{1} \ldots . . . . . . .4$ 4(2) wt. \% Anhydrite ${ }^{1}$........... 3.5(5) wt. \% Gypsum $^{1}$.......... 2.2(5) wt. \% K-spar ${ }^{1} \quad \ldots \ldots \ldots \ldots . . .1 .6(5)$ wt. $\%$ Bassanite $^{1}$........ 1.1(3) wt. \% Magnetite ${ }^{1} \ldots . .$. ... $0.5(5)$ wt. $\%$ $\begin{array}{ll}\text { Quartz }^{1} \ldots \ldots \ldots \ldots . & 0.5(3) \text { wt. } \%\end{array}$ (crystal angles around $\left.120^{\circ}\right)^{2}$
- Coarse-grained grey hematite (passive observations) $)^{2}$

- High iron variability in the member ${ }^{3}$

- Overall low Mn abundances ${ }^{4}$

- Iron oxide composition ${ }^{3}$ 


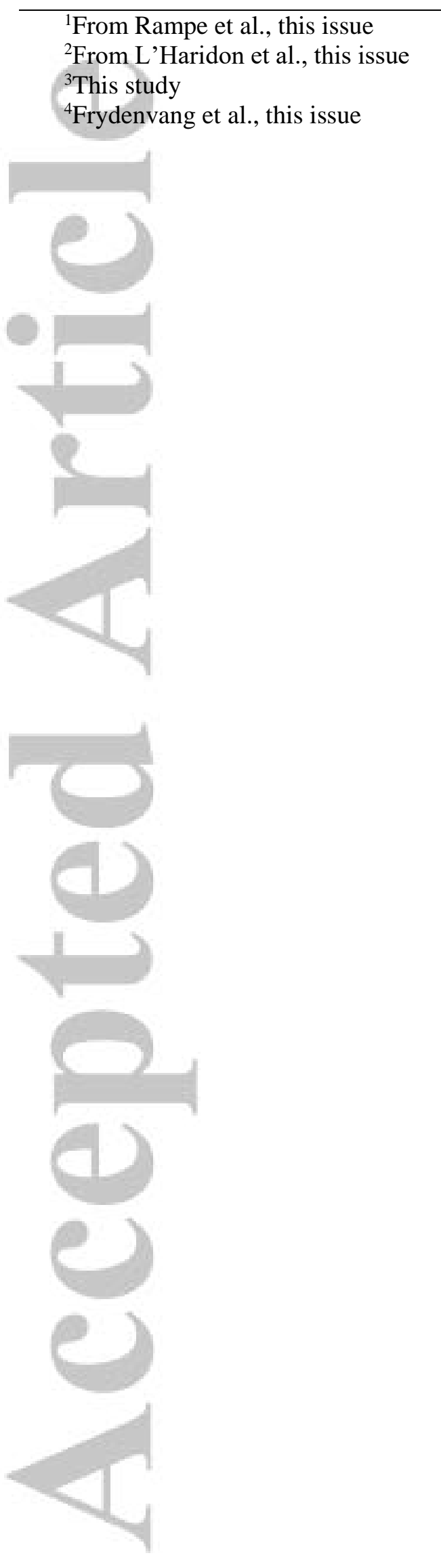

